Hydrol. Earth Syst. Sci. Discuss., doi:10.5194/hess-2016-247, 2016

Manuscript under review for journal Hydrol. Earth Syst. Sci.

Published: 23 May 2016

(c) Author(s) 2016. CC-BY 3.0 License.

1

2

3

$4{ }^{1}$ Laboratory of Critical Zone Evolution, School of Earth Sciences, China University of

5 Geosciences, Wuhan 430074, China;

$6{ }^{2}$ Canik Basari University, Faculty of Architecture and Engineering, Civil Engineering

7 Department, Samsun, Turkey;

$8 \quad{ }^{3}$ Department of Water Engineering, Shahid Bahonar University of Kerman, Kerman, Iran;

$9{ }^{4}$ School of Enviromental studies, China University of Geosciences, Wuhan 430074, China;

10

11

12

13

14

15

16

17

18

19

20

21

22

23

\section{Comparison of six different soft computing methods in modeling} evaporation in different climates 
Abstract: Evaporation plays important roles in regional water resources management, terrestrial ecological process and regional climate change. This study investigated the abilities of six different soft computing methods, Multi-layer perceptron (MLP), generalized regression neural network (GRNN), fuzzy genetic (FG), least square support vector machine (LSSVM), multivariate adaptive regression spline (MARS), adaptive neuro-fuzzy inference systems with grid partition (ANFIS-GP), and two regression methods, multiple linear regression (MLR) and Stephens and Stewart model (SS) in predicting monthly Ep. Long-term climatic data at eight stations in different climates, air temperature $(T a)$, solar radiation $(R g)$, sunshine hours $(H s)$, relative humidity $(R H)$ and wind speed (Ws) during 1961-2000 are used for model development and validation. The first part of applications focused on testing and comparing the model accuracies using different local input combinations. The results showed that the models have different accuracies in different climates and the MLP model performed superior to the other models in predicting monthly Ep at most stations, while GRNN model performed better in Tibetan Plateau. The accuracies of above models ranked as: MLP, GRNN, LSSVM, FG, ANFIS-GP, MARS and MLR. Generalized models were also developed and tested with data of eight stations. The overall results indicated that the soft computing techniques generally performed better than the regression methods, but MLR and SS models can be more preferred at some climatic zones instead of complex nonlinear models, for example, the BJ, CQ and HK stations.

Keywords: Pan evaporation; soft computing techniques; regression methods; model comparison

\section{Introduction}

Evaporation is the process of conversion of liquid water to water vapor, which depends on the differences in vapor pressure and air between the surface and surrounding atmosphere 
(Penman 1948; Kisi, 2013; Kim et al., 2015). Pan evaporation (Ep), which is a major component of hydrological cycle, plays important roles in scheduling water resources and designing of irrigation systems. It has been widely used as an index of lake and reservoir evaporation, potential or reference crop evapotranspiration and irrigation (Snyder 1993). There are many factors influencing the rates of $E p$, including solar radiation $(\mathrm{Rg})$, air temperature $(\mathrm{Ta})$, relative humidity $(R H)$, sunshine hours $(H s)$ and wind speed $(W s)$. The quantitative effects of different climatic parameters on $E p$ variations in different regions is still one of the less understood aspects in the hydrologic cycle. Therefore, proper estimation and prediction of $E p$ is of great importance to integrated water resources management and modeling studies.

The direct measurements of Ep are spatially and temporally limited due to some instrumental and practical issues (Shirsath and Singh, 2010; Shiri et al., 2014). Many researchers have tried to estimate the evaporation through indirect methods using climatic variables, for example, many empirical or semi-empirical equations have been developed for estimating $E p$ as a function of meteorological data (Stephens and Stewart 1963; Piri et al., 2009), but some of these techniques require the data which are often incomplete or not always available for many locations (Sharda et al., 2008; Majidi et al., 2015). Recently, the advanced soft computing techniques (such as artificial neural network, ANN) have been successfully applied for modeling Ep due to its ability to learn complex and non-linear relationships that are difficult to model with conventional techniques (Sudheer et al., 2002; Kisi and Ozturk, 2007; Kim and Kim, 2008; Kisi, 2009b; Rahimikhoob, 2009; Guven and Kisi, 2011; Kim et al., 2013; Goyal et al., 2014; Shiri et al., 2015; Kisi et al., 2016), for example, Kisi (2009a) investigated the abilities of three different ANN techniques and it was found that the MLP and radial basis neural network (RBNN) computing techniques could be employed successfully to model the evaporation process using the available climatic data; Piri et al. (2009) improved the ANN 
model by incorporating an autoregressive external input (ARX) component and evaluated the models for Ep estimation at a site in hot and dry climate of Southeast Iran. The results showed that NNARX is better than the ANN and Marciano method, the models with inputs of wind and vapor pressures performed much better than the ones with temperature and dew point; Chang et al. (2010) proposed a self-organizing map neural network (SOMN) to assess the variability of daily evaporation based on meteorological variables, the results demonstrated that the topological structures of SOMN could give a meaningful map to present the clusters of meteorological variables and the networks could well estimate the daily evaporation (Kim et al., 2015). Kim et al. (2012) applied multilayer perceptron-neural networks (MLP), generalized regression neural networks (GRNN) and support vector machine-neural networks (SVM) to estimate Ep in temperate and arid climatic zones and the results indicated that these ANN models performed better than the emprical Linacre model and MLR model. Goyal et al. (2014) investigated the abilities of ANN, Least Squares Support Vector Machine (LSSVM), Fuzzy Logic (FG), Adaptive Neuro-Fuzzy Inference System (ANFIS) techniques, Hargreaves and Samani method (HGS), as well as the Stephens-Stewart (SS) method to improve the accuracy of daily Ep estimation in sub-tropical climates of India. The results showed that the above soft computing models outperformed the HGS and SS methods, and the LSSVM and FG models produced the highest accuracies. Kisi (2015) investigated the accuracy of LSSVM, multivariate adaptive regression splines (MARS) and M5 Model Tree (M5Tree) in modeling Ep at Mersin and Antalya stations in Mediterranean region of Turkey, which indicated that the LSSVM model could be successfully used for estimating Ep using local input and output data while the MARS model performed better than the LSSVM model in case of without local input and outputs. Several studies have also been performed in order to compare and assess the Ep models with limited data around the world (Kisi and Cengiz, 2013; Majidi et al., 2015). On the contrary, only a few studies have been conducted to find the most appropriate methods 
to estimate $E p$, and most of these studies focused on comparing only two or three models. Therefore, there is no clear consensus on which methods are better to employ when lacking important long term measured data such as radiation and heat fluxes. Meanwhile, the Ep models are only tested at few number of stations in literature, for example, Keskin et al. (2004) only compared the FG model with empirical Penman method at Lake Eğirdir in Turkey; Sanikhani et al. (2012) compared two different ANFIS models including grid partitioning (GP) and subtractive clustering (SC), in modeling Ep at San Francisco and San Diego in California, however, there are almost no studies using large number of stations $(>3)$ for obtaining more generalized conclusions. In addition, there are not any studies in literature that compare different methods in estimating $E p$ at different climates (for example, the arid continental climate, desert climate, semi humid monsoon climate, plateau climate and the tropical maritime monsoon climate), which provided an impetus for the present investigation for revealing a more robust and applicable Ep estimation model.

Considering the importance of the evaporation in either irrigation management or hydrological modeling, the aim of this study is to investigate capability and usability of six different soft computing methods, ANFIS-GP, FG, GRNN, LSSVM, MARS and MLP, and two regression methods, MLR and SS, in modeling Ep using different climatic input combinations of $R g, T a, H s, R H$ and Ws. Data from eight stations in different climatic zones are used for training and testing above models. The model performances will be compared and discussed through: (i) estimating Ep of each station using different local input combinations; (ii) estimating Ep of eight stations using generalized ANFIS-GP, FG, GRNN, LSSVM, MARS, MLP, MLR and SS models. To the knowledge of the authors, no similar studies have been reported using above mentioned methods for modeling Ep, this will be the first study to compare the accuracy of multiple soft computing models for Ep estimation in different climates. 
Hydrol. Earth Syst. Sci. Discuss., doi:10.5194/hess-2016-247, 2016

\section{Methods and materials}

\subsection{Modeling strategies}

\subsection{Multi-layer perceptron neural network}

Fig. 1

MLP is well-known and efficient neural network widely used for a variety of problems such as classification, time series modeling and regression. MLPs are organized hierarchically networks by several layers, including an input layer, hidden layer(s) and an output layer (Zounemat-Kermani et al., 2013; Wang et al., 2016b). There are one or more hidden layers between the input and output layers which are connected by neurons (including synaptic weights, biases and activation or transfer functions). Each neuron receives its input value(s) from the input vector (or the antecedent hidden layer's output) and then calculates a weighted sum of input values passing through the transfer function, which generates the output of the neuron (Fig. 1a). MLPs are feed-forward networks, using the error back-propagation (BP) algorithm for network training. In the BP algorithm, an iterative process changes the weights and biases of the network to optimize the solution by reducing the overall error between the output and target (generally the observed parameters) values. More details about the MLP model can be found in Kisi (2009b) and Zounemat-Kermani (2012).

\subsection{Generalized regression neural network}

The GRNN model has a parallel structure, but they do not use an iterative process for learning procedure between the input and output variables. The structure of GRNN consists of four consequent layers, namely the 1) input, 2) pattern, 3) summation, and 4) output layers (see Fig.1b for a schematic diagram of a GRNN network). In the first layer, the total number of input variables is equal to the number of input units. Input data are linked to the second layer where each neuron presents a training pattern. The second layer sends processed information 
to the third (summation) layer through the pattern neurons. In the summation layer, there are two types of S-summation and D-summation neurons, which are connected to the pattern layer unit (Zounemat-Kermani, 2014). The sum of the weighted responses of the second layer is calculated by the S-summation neurons, while the D-summation neurons compute the unweighted outputs. Finally, in the output layer, the division of the output of each S-summation neuron by D-summation neuron gives the output value. More descriptions about the GRNN model can be seen from Cigizoglu and Alp (2006).

\subsection{Grid partitioning adaptive neuro-fuzzy inference system}

Fig. 2

ANFIS refers to a multi-layer adaptive network combined with neural network analogy with the fuzzy inference system. It consists of five consecutive layers (fuzzification, product, normalization, de-fuzzification and output) in an implementation procedure of different node functions to learn and adjust the parameters in a fuzzy inference system (Fig. 2). A hybrid learning algorithm, including forward and backward passes is utilized for reducing calculated errors and training phase. With the calculation of the least squared error, the consequent parameters are updated, whereas, the premise parameters are fixed. Hence, in the backward pass the consequent parameters are fixed and the premise parameters are updated through the gradient descent algorithm (Kisi and Ozturk, 2007; Zounemat-Kermani and Teshnehlab, 2008; Khayam et al., 2012).

Membership functions and fuzzy inference parameters are identified according to the adjustment of premise and consequent parameters by an iterative process of the forward and backward passes. Construction of ANFIS models is based on the partitioning of the inputoutput data for establishing the rule base system. In this respect, various approaches such as ANFIS-GP, subtractive clustering and fuzzy c-means methods can be applied. 
In this study the Sugeno model, which is the most commonly used system, along with the grid partitioning method is applied for modelling evapotranspiration. The reader can find out more details about ANFIS-GP in several available publications (Jang, 1993; Terzi et al., 2006; Khayam et al., 2012).

\subsection{Fuzzy-genetic algorithm}

The hybrid FG algorithm combines a meta-heuristic algorithm (genetic algorithm) and an adaptive fuzzy inference system (AFIS). In the AFIS, the input vectors along with the corresponding output(s) are introduced to the fuzzy system which is established based on the fuzzy logic approach. For further information about fuzzy logic, the reader is referred to related reports (Zounemat-Kermani and Scholz, 2013).

Genetic algorithms (GAs) are stochastic search algorithm based on the mechanics of natural genetics and natural selection which can be used for optimization problems. Getting the advantage of using the evolutionary mechanism, they are capable of searching large solution spaces efficiently. GA is composed of three main stages, namely, population initialization, GA operators (reproduction, crossover, and mutation) and evaluation (Kisi and Tombul, 2013). In this study, the proposed hybrid FG model is based on a model wherein the membership functions' parameters (e.g. center and width of Gaussian MFs) are optimized using a GA algorithm. The objective function of the genetic algorithm optimizer is the minimization of the error criterion (e.g. RMSE) of prediction made by an AFIS model (Kisi, 2009; Ganjidoost et al., 2015).

\subsection{Least-Squares support vector machine}

The SVM is based on a statistical learning theory which projects the input data classes to a higher dimensional feature space. The aim of the SVM algorithm is searching for an optimum hyper-plane with the minimum distance to the observed values. The algorithm is efficient, 
quick and converging procedure to the global optimum (Mesbah et al., 2015; Lu et al., 2016). However, the SVM algorithm has been modified and improved, referring to the LeastSquares-SVM (LSSVM) (Suykens and Vandewalle, 1999). In addition to have all the merits of the original SVM, LSSVM has become simpler and more rapid. This issue is caused by the structure of the LSSVM algorithm which solves a group of linear equations instead of solving a quadratic programming problem in the SVM method. LSSVM gets the advantage of the applying equality constraints (in exchange for traditional inequality constraints of SVM) and implements the sum of squared regression errors in the training process. Further details about the main equations and complete explanations of this subject can be found in Suykens and Vandewalle (1999) and Kisi (2015).

\subsection{Multivariate adaptive regression splines}

MARS, introduced by Friedman (1991), is categorized as a nonparametric regression method. MARS divides the space of each independent variable into split various regions called subregions. For each sub-region a unique mathematical regression equation is defined. A relationship is developed for each sub-region of the independent variable to the output (response) of the system based on the attained mathematical equation. This whole process is conducted by a stepwise procedure consists of backward and forward steps. In the forward step, a set of appropriate input variables is selected and split. However, split process in the forward step might generate an over-fitted complex model resulting in poor performance. Thereafter, in the backward step unnecessary variables will be eliminated (Adamowski et al., 2012; Kisi, 2015). For more detailed information on the development of the MARS models used throughout in this research the reader can refer to Shardaet al. (2008) and Kisi (2015).

\subsection{Multiple Linear Regressions}


MLR is a technique utilized to model the linear relationship between a dependent variable and one or more independent variables. The dependent variable is sometimes additionally called the predictors. MLR is depends on least squares: the model is fit such that the sum of squares of differences of estimated and observed values is minimized (http://tree.ltrr.arizona.edu/webhome/dmeko/geos585a.html\#cLesson11). MLR is probably the most widely used method in hydrology and climatology for developing models to reconstruct or analysis the long-term variations of climatic factors in literature. In this study, MLR models are developed using the same data set which was used to train and test the above soft computing models.

\subsection{Stephens and Stewart Model}

Stephens and Stewart (SS) model is an empirical linear equation and requires only radiation and temperature data (Stephens and Stewart 1963). This model was reported as the best among 23 models (Al-Shalan and Salih, 1987; Sudheer et al., 2002; Shirsath and Singh, 2010), which can be expressed as $E p=R g(a+b \times T a)$, where $a$ and $b$ are fitting constants (determined on the training data through least square fitting).

\subsection{Case study and data}

Fig. 3

In this study, monthly climatic data at eight stations of China Meteorological Administration (CMA) were used for developing and testing Ep models in different climates. Fig.3 shows the detailed geographical locations of above stations, which are named as HEB (latitude $45^{\circ} 45^{\prime} \mathrm{N}$, longitude $126^{\circ} 46^{\prime} \mathrm{E}, 142.3$ masl (m above sea level), ALT ( $47^{\circ} 44^{\prime} \mathrm{N}, 188^{\circ} 05^{\prime} \mathrm{E}, 735.3$ masl), MQ (38 $\left.38^{\prime} \mathrm{N}, 103^{\circ} 05^{\prime} \mathrm{E}, 1367 \mathrm{masl}\right), \mathrm{BJ}\left(39^{\circ} 48^{\prime} \mathrm{N}, 116^{\circ} 28^{\prime} \mathrm{E}, 31.3\right.$ masl), LSA $\left(29^{\circ} 40^{\prime} \mathrm{N}\right.$, $91^{\circ} 08^{\prime} \mathrm{E}, 3648.7$ masl), CQ $\left(29^{\circ} 35^{\prime} \mathrm{N}, 106^{\circ} 28^{\prime} \mathrm{E}, 259.1 \mathrm{masl}^{\prime}, \mathrm{HZ}\left(30^{\circ} 14^{\prime} \mathrm{N}, 120^{\circ} 10^{\prime} \mathrm{E}, 41.7\right.\right.$ masl) and $\mathrm{HK}\left(20^{\circ} 02^{\prime} \mathrm{N}, 110^{\circ} 21^{\prime} \mathrm{E}, 13.9\right.$ masl $)$. It should be noted that above stations are 
located at different climatic zones, for example, the HEB station is in the Northeast China with long and cold winter (semi humid temperate continental climate); the ALT station is in the Northwest China with arid continental climate; the MQ station is surrounded by the Tengger and Badan Jilin desert, which is characterized by continental desert climate with hot summer and cold winter, enough light and little rainfall amount; BJ is characterized by typical north temperate semi humid continental monsoon climate; LSA is in the zone of semi-arid plateau climate, which is called the sunlight city due to the sufficient sunshine resources in Tibetan Plateau; CQ is characterized by subtropical monsoon humid climate with more cloudy and foggy conditions; the HZ station is known as one of China's "four ovens" cities where summertime temperatures can reach to $40{ }^{\circ} \mathrm{C}$, which is characterized by hot and rainy in summer, cold and dry in winter due to the effects of East Asian atmospheric circulation, the terrain of Qinghai-Tibet Plateau and the North Pacific Ocean; the HK station is located at the northern margin of the low latitude tropics, which belongs to the tropical maritime monsoon climate. The detailed information about the geographical, climatic and hydrological conditions in this region can also be seen in Zhai et al. (1999) and Ding et al. (2006).

\section{Fig. 4}

The data used in this research cover 40 years (1961-2000) of monthly records of air temperature $(T a)$, solar radiation $(R g)$, sunshine durations $(H s)$, relative humidity $(R H)$, wind speed (Ws) and pan evaporation (Ep). For each station, $50 \%$ of the whole data were randomly chosen for training the Ep models and the remaining data were used for testing the models. The annual variations of Ep and associated climatic factors are shown clearly in Fig. 4, it is clear that Ep at MQ and LSA are generally higher than those at other stations, there are decreasing trends of Ep for ALT, BJ and HK stations during 1960-2000, and the most significant increasing trends of Ep are observed for LSA station. The Hs at CQ and HZ stations are much lower than those at other stations and the annual mean $\mathrm{Hs}$ is the highest 
among the eight stations. There are also slight increasing trends for $H s$ at most stations except $\mathrm{BJ}, \mathrm{HK}$ and $\mathrm{HZ}$ stations. The annual mean $R g$ is obviously higher at LSA station and $R g$ at CQ is the lowest, the $\mathrm{Rg}$ generally decreased from 1961 to 1990 and then increased for most stations. The $R H$ is generally larger than $75 \%$ at HZ, CQ and HK stations and lower than $50 \%$ for MQ and LSA stations. There are distinct differences for annual mean $T a$ at above eight stations, for example, $\mathrm{Ta}$ at $\mathrm{HK}$ is generally higher than $23^{\circ} \mathrm{C}$, while the highest annual mean Ta at HEB is lower than $5^{\circ} \mathrm{C}$. However, Ws is highest at HEB and lowest at CQ station, and Ws is decreasing from 1960 s to 2000 s at most stations.

Table 1

Fig. 5

Table 1 showed the monthly statistics of the climatic parameters, $\mathrm{x}_{\text {mean }}, \mathrm{S}_{\mathrm{x}}, \mathrm{C}_{\mathrm{v}}, \mathrm{C}_{\mathrm{x}}, \mathrm{x}_{\min }$ and $\mathrm{x}_{\max }$ denote the mean, standard deviation, variation coefficient, skewness, minimum and maximum values, respectively. It is clear that the monthly mean $E p$ is $4.35,4.72,7.26,5.09$, 6.35, 2.86, 3.65 and $5.00 \mathrm{~mm}$ for station HEB, ALT, MQ, BJ, LSA, CQ, HZ and HK, respectively. The mean $R g$ at LSA, MQ and ALT (20.41, 16.41 and $15.13 \mathrm{MJ} \mathrm{m}^{-2}$ ) are higher than those at other stations; the mean $\mathrm{Ta}$ at $\mathrm{HK}$ station is $24.08^{\circ} \mathrm{C}$, which is highest among all the stations. The Hs shows low variations for the MQ, BJ and LSA stations (see Cv values in Table1) and the monthly mean Hs at CQ (2.83 hour) is much lower than the other station. The monthly $R H$ is $65.44 \%, 57.99 \%, 44.82 \%, 57.29 \%, 44.39 \%, 79.15 \%, 78.04 \%$ and $84.14 \%$ for HEB, ALT, MQ, BJ, LSA, CQ, HZ and HK, respectively, which indicates that $R H$ is generally higher at lower latitudes. The Ws at HEB station is higher than other station in each month and the lowest monthly Ws $\left(1.36 \mathrm{~m} \mathrm{~s}^{-1}\right)$ is observed at CQ station. The monthly Ep, Ta, $H s$ and $R g$ are generally higher in summer and lower in winter months (Fig.5); the $R H$ is also lower in spring months for some stations such as HEB and MQ; the Ws is higher at spring and lower in summer months for most stations (Fig.5). For the HEB station, $R G$ shows low 
Hydrol. Earth Syst. Sci. Discuss., doi:10.5194/hess-2016-247, 2016

Manuscript under review for journal Hydrol. Earth Syst. Sci.

Published: 23 May 2016

(c) Author(s) 2016. CC-BY 3.0 License.
Hydrology and

Earth System

Sciences

Discussions
293

294

295

296

297

skewed distribution and has a relatively higher correlation with $E p(R=0.89)$; the $R H$ and Ws data have the lowest $(R=-0.30,0.26)$ correlation with $E p$. For the ALT station, the Ta data have a high skewness $\left(\mathrm{C}_{\mathrm{v}}=3.07\right)$ and high correlation with $E p(R=0.93)$. For the MQ station, the Hs shows the lower skewed distribution $\left(\mathrm{C}_{\mathrm{v}}=0.13\right)$ and has a positive correlation with $E p$ $(R=0.72)$; the $T a$ data have a higher skewness $\left(\mathrm{C}_{\mathrm{v}}=1.36\right)$ and the highest correlation with $E p$ ( $R=0.93)$. In similar, the $R g$ and $H s$ data show relatively higher skewness and correlations with $E p$ for the BJ, CQ and HK stations. At some cases, the correlations between Ta and $E p$ are also higher than those with $H s$, for example, the LSA $(R=0.75)$ and $\mathrm{HZ}(R=0.88)$ stations. It is clear from the statistical indices in Table 1 that each climatic variable have different correlations with $E p$, and $R g$, $H s$ and $T a$ variables seem to be the most effective parameters for predicting $E p$ with respect to the correlations.

\subsection{Evaluation criteria}

In this study, the ANFIS-GP, FG, GRNN, LSSVM, MARS, MLP, MLR and SS models were evaluated and compared with each other utilizing the mean absolute errors (MAE), root mean square errors (RMSE) and determination coefficient $\left(\mathrm{R}^{2}\right)$, which can be expressed as

$$
\begin{aligned}
& R M S E=\sqrt{\frac{1}{N} \sum_{i=1}^{N}\left(E p_{m, i}-E p_{o, i}\right)^{2}} \\
& M A E=\frac{1}{N} \sum_{i=1}^{n}\left|E p_{m, i}-E p_{o, i}\right| \\
& R^{2}=\frac{\left(\sum_{i=1}^{n}\left(E p_{m, i}-\overline{E p_{m}}\right)\left(E p_{o, i}-\overline{E p_{o}}\right)\right)^{2}}{\sum_{i=1}^{n}\left(E p_{m, i}-\overline{E p_{m}}\right)^{2} \sum_{i=1}^{n}\left(E p_{o, i}-\overline{E p_{o}}\right)^{2}}
\end{aligned}
$$
$E p_{o}$ are the modeled and observed pan evaporation. 


\section{Results and discussion}

This study compares six different soft computing methods, ANFIS-GP, FG, GRNN, LSSVM, MARS and MLP, and two empirical methods, MLR and SS, in modeling Ep using climatic inputs of $R g, T a, H s, R H$ and Ws. Data from eight stations, HEB, ALT, MQ, BJ, LSA, CQ, HZ and HK were utilized in the applications. The input combinations used for each model are provided in Table 2, the numbers after each model indicates the input combination. Two Gaussian membership functions were utilized for each ANFIS-GP and FG model. Different regularization constants and RBF kernel widths were tried for the LSSVM models and the optimal models that provided the least RMSE error in testing stage were obtained. For the GRNN models, different spread constants were tried. Different hidden node numbers were tried and the optimal ones were obtained for each MLP model.

Table 2

Table 3

Table 4

The training and testing results of the ANFIS-GP, FG, GRNN, LSSVM, MARS, MLP, SS and MLR models in predicting Ep of HEB station are shown in Table 3. It is clear from the table that the models with full weather data ( $R g, T a, H s, R H$ and $W s$ ) have the best accuracy. The MLP7 model performs superior to the other models in predicting Ep at HEB. The accuracy ranks of the applied soft computing models in testing period are: MLP, ANFIS-GP, FG, GRNN, MARS, LSSVM and MLR. It is clear from the first three input combinations that there is a slight difference between $R g$ and $T a$ and they are much more effective on modeling $E p$ at HEB station than the other variables. This is also confirmed by the $\mathrm{R}^{2}$ values given in Table 1. Comparisons of the simple two-input ( $R g$ and $T a)$ models clearly indicate that the ANFIS-GP4, GRNN4 and LSSVM4 models have better accuracy than those of the SS model while the FG4, MARS4 and MLP4 models give inferior results in testing period. Table 4 
gives the accuracy of the applied models in predicting Ep at ALT station. Similar to the HEB station, the models comprising whole weather inputs generally provide the best accuracy and the optimal MLP7 model outperforms the other models in predicting Ep at ALT station. The accuracy ranks of the models in testing stage are: MLP, LSSVM, ANFIS-GP, FG, MARS, GRNN and MLR. There is a slight difference between the $\mathrm{Rg}, \mathrm{Ta}$ and $\mathrm{Hs}$ parameters and these are also parallel to the correlations given in Table 1. Two-input soft computing models seem to have a better accuracy than the SS model in predicting Ep at ALT station in the testing stage.

Table 5

Table 6

The training and testing statistics of the soft computing models, SS and MLR in predicting Ep of MQ station are provided in Table 5. In this station, five-input models also have the best performance and the MLP7 model performs superior to the other models. The accuracy ranks of the 5-input models are: MLP, FG, ANFIS-GP, GRNN, MARS, MLR and LSSVM. From the first three inputs, it is clear that the $R g$ and $T a$ variables have more effects on $E p$ than the Hs in MQ station. The correlations in Table 1 also confirm these results. It is apparent from Table 5 that the SS model provides inferior results in comparison with the 2-input soft computing models at MQ station. Table 6 reports the training and testing results of the applied models in predicting Ep at BJ station. From the table, it is obvious that the models with full weather data generally have the best accuracy. The MLP model provides better performance than the other models with respect to MAE, RMSE and $\mathrm{R}^{2}$. The ranks of the applied models in testing accuracy are: MLP, LSSVM, GRNN, ANFIS-GP, FG, MARS and MLR. It is clear from the first three input combinations that the $R g$ which has a higher correlation with $E p$ (see Table 1) is much more effective on Ep than the $T a$ and $H s$ at BJ. Simple SS model seems to 
have better accuracy than the applied 2-input soft computing models in predicting Ep at BJ station in testing stage.

Table 7

Table 8

Table 7 compares the accuracy of the applied soft computing models in predicting Ep at LSA station. Similar to the previous stations, the best accuracies were generally obtained from fiveinput models and the GRNN model performs better than the other models with respect to MAE and RMSE statistics. The accuracies of the applied models in testing stage rank as: GRNN, MLP, LSSVM, MARS, FG, ANFIS-GP and MLR. The Ta seems to be the most effective parameter in predicting $E p$ at this station, which is also confirmed by the high correlation between $\mathrm{Ta}$ and Ep given in Table 1. The models with $\mathrm{Hs}$ input generally provide worse results than those comprising $R g$ input parameter. Two-input LSSVM4, ANFIS-GP4 and SS models have similar accuracy and they perform inferior to the FG4, GRNN4, MARS4 and MLP4 models. The accuracies of the ANFIS-GP, FG, GRNN, LSSVM, MARS, MLP, SS and MLR models in both training and testing stages are given in Table 8 for predicting Ep of CQ station. Unlike the previous stations, four-input models generally provide the best performance in this station. This implies that adding Ws input generally decreases the model accuracies even though it does not have a low correlation $(\mathrm{R}=0.58)$ with $E p$ at $\mathrm{CQ}$ station. The MLP6 and GRNN6 models have similar accuracies and they perform superior to the other models. The accuracy ranks of the above applied models in testing stage are: MLP, GRNN, FG, LSSVM, MARS, ANFIS-GP and MLR. Similar to the BJ station, the $R g$ input seems to have more effects on Ep than the Ta and $H s$ input at CQ station than the other variables even though the Hs has a higher correlation with Ep. Comparison of two-input models obviously shows that the SS model has a better accuracy than those of the other two-input soft computing models in testing period. 
The training and testing accuracy of the soft computing models, SS and MLR in predicting Ep of HZ station are provided in Table 9. In this station, four- and five-input models also have the best accuracies. The optimal MLP and GRNN models have similar performance and they perform superior to the other models in predicting Ep at HZ station. The performance ranks of the optimal models are: MLP, GRNN, MARS, FG, LSSVM, ANFIS-GP and MLR. Similar to the BJ station, the $R g$ variable which has a higher correlation with $E p$ (see Table 1) is much more effective on estimating $\mathrm{Ep}$ than the $\mathrm{Ta}$ and $\mathrm{Hs}$ at $\mathrm{HZ}$. Ta variable also provides better accuracy than the $H s$ in predicting Ep. Comparisons of simple two-input models clearly indicates that the MARS4 and MLP4 models have better accuracy than those of the SS model while the ANFIS-GP4, FG4, GRNN4 and LSSVM4 provide inferior results in testing stage. Table 10 compares the accuracy of the models in predicting Ep at $\mathrm{HK}$ station. From the table, it is clear that the best accuracies were obtained from five-input models in predicting Ep. The MLP model performs superior to the other models with respect to MAE, RMSE and $\mathrm{R}^{2}$ statistics. The accuracies of the applied models in testing period rank as: MLP, MLR, GRNN, MARS, LSSVM, ANFIS-GP and FG. The accuracies of the MLR and MLP model are close to each other. Therefore, simple MLR model can be preferred instead of more complex soft computing models in predicting Ep at HK station. Unlike the previous stations, the models comprising $\mathrm{Hs}$ input provide better accuracy than those which use only $\mathrm{Rg}$ or $\mathrm{Ta}$ input. The $R g$ variable also seems to be more effective on Ep than the $T a$ at $\mathrm{HZ}$ station. The difference among the two-input models is very small and the GRNN4 and SS models perform slightly better than the other two-input models in predicting Ep at HK station.

It can be seen from above analysis that adding $R H$ or Ws inputs into the applied models generally increased their accuracies in predicting Ep in all stations even though these 
parameters had the lowest correlation with Ep (see Table 1). This indicates the non-linear relationship between $R H(W s)$ and $E p$ and linear $\mathrm{R}^{2}$ indicator cannot show this phenomenon. General accuracies of the applied models are compared in Table 11. It is obvious that the MLP model provides much better scores than the other methods in predicting Ep at above eight stations (and data from all station) and the final accuracy ranks of the above models are: MLP, GRNN, LSSVM, FG, ANFIS-GP, MARS and MLR. In some stations (e.g., BJ, CQ), simple SS model performed superior to the two-input soft computing models and it can be preferred in these stations where $H s, R H$ and $W s$ parameters are not available.

Table 11

Figs.6-13 illustrates the estimates of the optimal models in testing phase for eight stations in the form of scatterplot. For HEP station, the fit line of the MARS model seems to be closer to the ideal line $(\mathrm{y}=\mathrm{x})$ while the MLP model has the highest $\mathrm{R}^{2}$ means less scattered estimates than the other models. All the soft computing models provide close estimates to the corresponding observed ones in ALT station while MLR generally tends to overestimation. For MQ station, the LSSVM, MARS and MLR models provide more scattered estimates than the ANN (MLP and GRNN) and fuzzy based ANFIS-GP and FG models. All the models generally have good estimates at the BJ, CQ, HK and HZ stations. In LSA station, the MLP, GRNN, LSSVM and MARS provide less scattered estimates than the fuzzy based ANFIS-GP, FG and MLR models. From Figs.6-13, it is clear that the MLP model generally provided less scattered estimates than the other models in all stations. The models generally provided the worst accuracy in LSA station. One of the main reasons of this may be the fact that the Ep has low correlations with the climatic input data at LSA in comparison with other stations. It is clear from Fig. 12 that the SS model provides less scattered estimates for the ALT, CQ and $\mathrm{HZ}$ in comparison with other stations. 
Hydrol. Earth Syst. Sci. Discuss., doi:10.5194/hess-2016-247, 2016

Fig. 7

Fig. 8

Fig. 9

Fig. 10

Fig. 11

Fig. 12

Fig. 13

The Ep data at all stations are further estimated using single generalized MLP, GRNN, MARS, LSSVM, ANFIS-GP, FG, MLR and SS models. The optimal models are obtained using training and testing data of above eight stations, the training and testing statistics of the applied models are compared in Table 12. Similar to the previous results, the best accuracies are obtained from the five-input models and the MLP model performs better than the other models. The accuracies of the applied models in testing stage rank as: MLP, GRNN, LSSVM, FG, ANFIS-GP, MARS and MLR. The $R g$ variable seems to be the most effective parameter in predicting $\mathrm{Ep}$ for data from all station, and the models with $\mathrm{Hs}$ input generally provides slightly better results than those comprising $\mathrm{Ta}$ input parameter. Two-input MARS4 and ANFIS-GP4 models perform inferior to the FG4, GRNN4, LSSVM4 and MLP4 models; the SS model has a lower accuracy than those of the other two-input soft computing models in testing period (Table 12). It is also observed that only Ta or Hs input seems to be insufficient for obtaining an accurate generalized $E p$ model and the model performances generally increase with input numbers, which implies that all above climatic parameters have positive effects on estimating Ep for most stations in different climates. The estimates of the generalized models are illustrated in Figs.6-13 (see the last scatterplot in each figure). It is clearly observed from the figures that the generalization significantly decreases models accuracy in estimating Ep at all stations. However, all the soft computing models generally 
have good generalization ability. Some underestimations of the high Ep values are clearly seen for the generalized models. Different data ranges in training and test stages may be the reason of this.

Table 12

\section{Conclusion}

This study investigated and compared the abilities of six different soft computing techniques, MLP, GRNN, LSSVM, FG, ANFIS-GP, MARS, and two regression methods, MLR and SS, in modeling Ep using different climatic input combinations of $\mathrm{Rg}$, Ta, $\mathrm{Hs}, \mathrm{RH}$ and Ws. The climatic data obtained from eight stations in different climatic zones were used as inputs for training and testing above models. In the first part of applications, the models with different local input combinations were compared with each other in estimating Ep at each station, separately. The results showed that the models with more inputs generally have better accuracies and the MLP model performed superior to the other models in predicting monthly $E p$ at most stations, however, the GRNN model performed better than the other models at LSA station with respect to MAE and RMSE statistics. The $R g$ and $T a$ variables are more effective on modeling Ep at most stations, while Ta seems to be the most important parameter in predicting Ep at LSA, and adding Ws to the input combinations even decreases the model accuracies. Sometimes, MLR model can be used for predicting Ep in tropic climate instead of more complex soft computing models, and SS model can also be adopted for some stations in regions of subtropical humid climate or temperate continental climate. The second part of applications focused on estimating Ep of all stations using generalized models, which could be successfully used for predicting $E p$ using different input combinations. The accuracies of the applied models rank as: MLP, GRNN, LSSVM, FG, ANFIS-GP, MARS and MLR. The 
$R g$ and $H s$ variables seem to be the most effective parameters in predicting $E p$ for data from all stations.

In summary, it is revealed in this study that the MLP models are the most appropriate for predicting Ep using limited climatic inputs in different climates. The present applications can be practically adopted in the field of water resources management for accurately mapping regional and global distributions of evaporation and related water resource storages.

\section{Acknowledgement}

This work was financially supported by the Special Fund for Basic Scientific Research of Central Colleges, China University of Geosciences, Wuhan (No.CUG150631), and the 111 Project (grant No. B08030). We would like to thank the China Meteorological Administration (CMA) for providing the meteorological and radiation data.

\section{References}

Adamowski, J., Chan, H.F., Prasher, S.O., Sharda, V.N., 2012. Comparison of multivariate adaptive regression splines with coupled wavelet transform artificial neural networks for runoff forecasting in Himalayan micro-watersheds with limited data. J. Hydroinfor. 14(3), $731-744$

Chang, F.G., Chang, L.C., Kao, H.S., Wu, G.R., 2010. Assessing the effort of meteorological variables for evaporation estimation by self-organizing map neural network, J. Hydrol. 384, $118-129$

Cigizoglu, H.K., Alp, M., 2006. Generalized regression neural network in modelling river sediment yield. Adv. Eng. Soft. 37(2), 63-68.

Ding, Y.H., Ren, G. Y., Shi, G.Y., Gong, P., Zheng, X.H., Zhai, P.M., Luo, Y., 2006. National assessment report of climate change (I): climate change in China and its future trend. Adv. Clim. Change Res. 2(1), 3-8. 
Hydrol. Earth Syst. Sci. Discuss., doi:10.5194/hess-2016-247, 2016

Friedman, J. H., 1991. Multivariate adaptive regression splines. The annals of statistics, 1-67. Ganjidoost, H., Mousavi, S.J., Soroush, A., 2015. Adaptive Network-Based Fuzzy Inference Systems Coupled with Genetic Algorithms for Predicting Soil Permeability Coefficient. Neural Proce. Lett. 1-27.

Goyal, M.K., Bharti, B., Quilty, J., Adamowski, J., Pandey, A., 2014. Modeling of daily pan evaporation in sub-tropical climates using ANN, LS-SVR, Fuzzy Logic, and ANFIS. Expert Syst. Appl. 41 (11), 5267-5276.

Guven, A., Kisi, O., 2011. Daily pan evaporation modeling using linear genetic programming technique. Irrig. sci. 29(2),135-145.

Jang, J.S.R., 1993. ANFIS: adaptive-network-based fuzzy inference system. IEEE Trans. Syst. Man Cybern. B 23(3), 665-685.

Keskin, M.E., Terzi, O., Taylan, D., 2004. Fuzzy logic model approaches to daily pan evaporation estimation in western Turkey. Hydrol. Sci. J. 49 (6), 1001-1010.

Khayyam, H., Nahavandi, S., Davis, S., 2012. Adaptive cruise control look-ahead system for energy management of vehicles. Expert sys. appl. 39(3), 3874-3885.

Kim, S., Kim, H.S., 2008. Neural networks and genetic algorithm approach for nonlinear evaporation and evapotranspiration modeling. J. Hydrol. 35, 299-317.

Kim, S., Shiri, J., Kisi, O., 2012. Pan evaporation modeling using neural computing approach for different climatic zones. Water Resour. Manage. 26(11), 3231-3249.

Kim, S., Shiri, J., Kisi, Ö., Singh, V. P. 2013. Estimating daily pan evaporation using different data-driven methods and lag-time patterns. Water Resour. Manage. 27(7), 2267-2286.

Kim, S., Shiri, J., Singh, V. P., Kisi, Ö., Landeras, G., 2015. Predicting daily pan evaporation by soft computing models with limited climatic data. Hydrol. Sci. J. 60(6), 1120-1136.

Kisi, O., Ozturk, O., 2007. Adaptive neurofuzzy computing technique for evapotranspiration estimation. J. irrig. drainage eng. 133 (4), 368-379. 
Kisi, O., 2009a. Daily pan evaporation modelling using multi-layer perceptrons and radial basis neural networks. Hydrol. process. 23 (2), 213-223.

Kisi, O., 2009b. Fuzzy genetic approach for modeling reference evapotranspiration. J. irrig. drainage eng. 136(3), 175-183.

Kisi, O., Cengiz, T.M., 2013. Fuzzy genetic approach for estimating reference evapotranspiration of Turkey: Mediterranean Region. Water Resour. Manag. 27, 3541-3553. Kisi, O., Tombul, M., 2013. Modeling monthly pan evaporations using fuzzy genetic approach. J. Hydrol. 477, 203-212.

Kisi, O., 2015. Pan evaporation modeling using least square support vector machine, multivariate adaptive regression splines and M5 model tree. J. Hydrol. 528, 312-320.

Kisi, O., Genc, O., Dinc, S., Zounemat-Kermani, M., 2016. Daily pan evaporation modeling using chi-squared automatic interaction detector, neural networks, classification and regression tree. Comput. Elect. Agr. 122, 112-117.

Li, Z., Chen, Y., Shen, Y., Liu, Y., Zhang, S., 2013. Analysis of changing pan evaporation in the arid region of Northwest China. Water Res. Res. 49(4), 2205-2212.

Lin, G.F., Lin, H.Y., Wu, M.C., 2013. Development of a support-vector-machine-based model for daily pan evaporation estimation. Hydrol. Process. 27 (22), 3115-3127.

Lu, C., Chen, J., Hong, R., Feng, Y., Li, Y., 2016. Degradation trend estimation of slewing bearing based on LSSVM model. Mech. Sys. Sig. Process. 76, 353-366.

Majidi, M., Alizadeh, A., Farid, A., Vazifedoust, M., 2015. Estimating Evaporation from Lakes and Reservoirs under Limited Data Condition in a Semi-Arid Region. Water Resour. Manage. 29(10), 3711-3733.

Mesbah, M., Soroush, E., Azari, V., Lee, M., Bahadori, A., Habibnia, S., 2015. Vapor liquid equilibrium prediction of carbon dioxide and hydrocarbon systems using LSSVM algorithm. J. Supercri. Fluids, 97, 256-267. 
Hydrol. Earth Syst. Sci. Discuss., doi:10.5194/hess-2016-247, 2016

Piri, J., Amin, S., Moghaddamnia, A., Keshavarz, A., Han, D., Remesan, R., 2009. Daily pan evaporation modeling in a hot and dry climate. J. Hydrol. Engin. 14(8), 803-811.

Rahimikhoob, A., 2009. Estimating daily pan evaporation using artificial neural network in a semi-arid environment. Theoret. Appl. Climatol. 98(1-2), 101-105.

Sanikhani, H., Kisi, Ö., Nikpour, M.R., Dinpashoh, Y., 2012. Estimation of daily pan evaporation using two different adaptive neuro-fuzzy computing techniques. Water Resour. Manage. 26(15), 4347-4365.

Sharda, V.N., Prasher, S.O., Patel, R.M., Ojasvi, P.R., Prakash, C., 2008. Performance of Multivariate Adaptive Regression Splines (MARS) in predicting runoff in mid-Himalayan micro-watersheds with limited data. Hydrol. Sci. J. 53(6), 1165-1175.

Shiri, J., Sadraddini, A.A., Nazemi, A.H., Kisi, O., Landeras, G., Fakheri Fard, A., Marti, P., 2014. Generalizability of gene expression programming-based approaches for estimating daily reference evapotranspiration in coastal stations of Iran. J. Hydrol. 508, 1-11.

Shiri, J., Marti, P., Nazemi, A.H., Sadraddini, A.A., Kisi, O., Landeras, G., Fakheri Fard, A., 2015. Local vs. external training of neuro-fuzzy and neural networks models for estimating reference evapotranspiration assessed through k-fold testing. Hydrol. Res. 46(1), 72-88.

Shirsath, P. B., Singh, A. K., 2010. A comparative study of daily pan evaporation estimation using ANN, regression and climate based models. Water Resour. Manage. 24(8), 1571-1581.

Stephens, J.C., Stewart, E.H., 1963 A comparison of procedures for computing evaporation and evapotranspiration. Publication 62, international association of scientific hydrology. International Union of Geodynamics and Geophysics, Berkeley, CA, pp. 123-133.

Suykens, J. A., Vandewalle, J., 1999. Least squares support vector machine classifiers. Neural Process. Lett. 9(3), 293-300.

Sudheer, K.P., Gosain, A.K., Rangan, D.M., Saheb, S.M., 2002. Modelling evaporation using an artificial neural network algorithm. Hydrol. Process. 16, 3189-3202. 
Hydrol. Earth Syst. Sci. Discuss., doi:10.5194/hess-2016-247, 2016

Terzi, O., ErolKeskin, M., Dilek Taylan, E., 2006. Estimating evaporation using ANFIS. J. irrig. drainage eng. 132(5), 503-507.

Terzi, O., Keskin, M.E., 2010. Comparison of artificial neural networks and empirical equations to estimate daily pan evaporation. Irrig. Drain. 59, 215-225.

Wang, L., Kisi, O., Zounemat-Kermani, M., Hu, B., Gong, W., 2016. Modeling and comparison of hourly photosynthetically active radiation in different ecosystems. Renew. Sust. Energ. Reviews 56, 436-453.

Wang, L., Kisi, O., Zounemat-Kermani, M., Salazar, G. A., Zhu, Z., Gong, W., 2016. Solar radiation prediction using different techniques: model evaluation and comparison. Renew. Sust. Energ. Reviews 61, 384-397.

Zounemat-Kermani, M., 2012. Hydrometeorological parameters in prediction of soil temperature by means of artificial neural network: Case study in Wyoming. J. Hydrol. Eng. 18(6), 707-718.

Zounemat-Kermani, M., 2014. Principal component analysis (PCA) for estimating chlorophyll concentration using forward and generalized regression neural networks. Appl. Artif. Intel. 28 (1), 16-29.

Zounemat-Kermani, M., Scholz, M., 2013. Modeling of dissolved oxygen applying stepwise regression and a template-based fuzzy logic system. J. Environ. Eng. 140(1), 69-76.

Zounemat-Kermani, M., Teshnehlab, M., 2008. Using adaptive neuro-fuzzy inference system for hydrological time series prediction. Appl. Soft Comput. 8(2), 928-936.

Zounemat-Kermani, M., Kisi, O., Rajaee, T., 2013. Performance of radial basis and LM-feed forward artificial neural networks for predicting daily watershed runoff. Appl. Soft Comput. 13(12), 4633-4644.

Zhai, P., Sun, A., Ren, F., Liu, X., Gao, B., Zhang, Q. 1999. Changes of climate extremes in China. In Weather and Climate Extremes (pp. 203-218). Springer Netherlands. 
Hydrol. Earth Syst. Sci. Discuss., doi:10.5194/hess-2016-247, 2016

Manuscript under review for journal Hydrol. Earth Syst. Sci.

Published: 23 May 2016

(c) Author(s) 2016. CC-BY 3.0 License.
Hydrology and
610

Table 1.Monthly statistical parameters of each data set for each station

\begin{tabular}{|c|c|c|c|c|c|c|c|c|}
\hline Station & Dataset & $\mathbf{x}_{\text {mean }} \quad \mathbf{S}_{\mathbf{x}}$ & $\mathbf{C}_{\mathbf{v}}$ & $\mathbf{x}_{\min }$ & $\mathbf{x}_{\max }$ & $R$ & & \\
\hline \multirow[t]{6}{*}{ HEB } & $R g$ & 12.98 & 5.35 & 0.41 & 0.00 & 3.68 & 28.71 & 0.89 \\
\hline & Ta & 4.17 & 14.52 & 3.48 & -0.25 & -24.71 & 25.25 & 0.86 \\
\hline & Hs & 7.02 & 1.59 & 0.23 & -0.25 & 2.82 & 10.89 & 0.79 \\
\hline & $\boldsymbol{R H}$ & 65.44 & 11.01 & 0.17 & -0.44 & 36.23 & 85.06 & -0.36 \\
\hline & Ws & 3.69 & 0.97 & 0.26 & 0.61 & 1.88 & 6.69 & 0.26 \\
\hline & $E_{P}$ & 4.35 & 3.27 & 0.75 & 0.44 & 0.16 & 12.96 & 1 \\
\hline \multirow[t]{6}{*}{ ALT } & $\boldsymbol{R g}$ & 15.13 & 7.21 & 0.48 & -0.06 & 2.34 & 27.69 & 0.92 \\
\hline & Ta & 4.54 & 13.95 & 3.07 & -0.25 & -25.08 & 24.87 & 0.93 \\
\hline & Hs & 8.2 & 2.52 & 0.31 & -0.25 & 1.92 & 12.66 & 0.90 \\
\hline & $\boldsymbol{R H}$ & 57.99 & 13.41 & 0.23 & 0 & 30.1 & 86.77 & -0.89 \\
\hline & Ws & 2.40 & 0.99 & 0.41 & 0.05 & 0.31 & 5.46 & 0.69 \\
\hline & $E_{P}$ & 4.72 & 3.84 & 0.81 & 0.33 & 0.15 & 13.79 & 1 \\
\hline \multirow[t]{6}{*}{ MQ } & $R g$ & 16.41 & 4.98 & 0.30 & 0.07 & 7.21 & 26.9 & 0.92 \\
\hline & Ta & 8.33 & 11.32 & 1.36 & -0.19 & -15.46 & 25.72 & 0.93 \\
\hline & Hs & 8.37 & 1.12 & 0.13 & 0.30 & 5.47 & 11.38 & 0.72 \\
\hline & $\boldsymbol{R H}$ & 44.82 & 9.06 & 0.2 & 0.12 & 24.3 & 74.58 & -0.29 \\
\hline & Ws & 2.68 & 0.55 & 0.20 & 0.08 & 1.23 & 4.32 & 0.55 \\
\hline & $E_{P}$ & 7.26 & 4.45 & 0.61 & 0.10 & 0.42 & 15.89 & 1 \\
\hline \multirow[t]{6}{*}{ BJ } & $R g$ & 14.61 & 4.94 & 0.34 & 0.05 & 5.14 & 25.59 & 0.91 \\
\hline & Ta & 12.20 & 10.74 & 0.88 & -0.17 & -7.6 & 29.56 & 0.75 \\
\hline & Hs & 7.41 & 1.42 & 0.19 & 0.06 & 3.79 & 11.21 & 0.76 \\
\hline & $\boldsymbol{R H}$ & 57.29 & 13.70 & 0.24 & 0.02 & 21.86 & 85.52 & 0.09 \\
\hline & Ws & 2.50 & 0.67 & 0.27 & 0.49 & 1.07 & 4.65 & 0.14 \\
\hline & $E_{P}$ & 5.09 & 2.83 & 0.56 & 0.70 & 0.85 & 15.63 & 1 \\
\hline \multirow[t]{6}{*}{ LSA } & $R g$ & 20.41 & 4.20 & 0.21 & 0.11 & 10.39 & 30.69 & 0.68 \\
\hline & $T a$ & 7.82 & 6.37 & 0.81 & -0.21 & -5.16 & 18.19 & 0.75 \\
\hline & Hs & 8.19 & 0.96 & 0.12 & -0.59 & 4.66 & 10.55 & 0.18 \\
\hline & $\boldsymbol{R H}$ & 44.39 & 15.10 & 0.34 & 0.30 & 15.36 & 76.61 & 0.19 \\
\hline & Ws & 1.90 & 0.46 & 0.24 & 0.30 & 0.92 & 3.41 & 0.34 \\
\hline & $E_{P}$ & 6.35 & 2.23 & 0.35 & 0.36 & 2.15 & 13.28 & 1 \\
\hline \multirow[t]{6}{*}{ CQ } & $R g$ & 8.80 & 4.69 & 0.53 & 0.43 & 0 & 21.32 & 0.92 \\
\hline & Ta & 17.93 & 7.46 & 0.42 & -0.10 & 0.64 & 30.90 & 0.85 \\
\hline & Hs & 2.83 & 2.02 & 0.71 & 0.91 & 0 & 9.19 & 0.94 \\
\hline & $\boldsymbol{R H}$ & 79.15 & 8.55 & 0.11 & -4.66 & 6.97 & 90.30 & -0.40 \\
\hline & Ws & 1.36 & 0.34 & 0.25 & -0.12 & 0.64 & 2.13 & 0.58 \\
\hline & $E_{P}$ & 2.86 & 1.94 & 0.68 & 0.87 & 0.54 & 9.32 & 1 \\
\hline \multirow[t]{6}{*}{ HZ } & $R g$ & 11.63 & 4.20 & 0.36 & 0.54 & 3.93 & 24.83 & 0.94 \\
\hline & Ta & 16.45 & 8.46 & 0.51 & -0.06 & -0.01 & 31.03 & 0.88 \\
\hline & Hs & 4.99 & 1.74 & 0.35 & 0.63 & 1.19 & 11.25 & 0.80 \\
\hline & $\boldsymbol{R H}$ & 78.04 & 5.63 & 0.07 & -0.80 & 53.74 & 90.42 & -0.04 \\
\hline & Ws & 2.24 & 0.43 & 0.19 & 0.05 & 1.01 & 3.58 & 0.13 \\
\hline & $E_{P}$ & 3.65 & 1.94 & 0.53 & 0.84 & 0.74 & 11.33 & 1 \\
\hline \multirow[t]{2}{*}{ HK } & $R g$ & 13.86 & 4.33 & 0.31 & -0.05 & 4.06 & 24.34 & 0.90 \\
\hline & Ta & 24.08 & 4.07 & 0.17 & -0.55 & 13.21 & 29.83 & 0.81 \\
\hline
\end{tabular}


Hydrol. Earth Syst. Sci. Discuss., doi:10.5194/hess-2016-247, 2016

Manuscript under review for journal Hydrol. Earth Syst. Sci.

Published: 23 May 2016

(c) Author(s) 2016. CC-BY 3.0 License.

\begin{tabular}{llllllll}
$\boldsymbol{H} \boldsymbol{s}$ & 5.83 & 1.96 & 0.34 & -0.26 & 0.47 & 9.94 & 0.89 \\
$\boldsymbol{R H}$ & 84.14 & 3.61 & 0.04 & -0.52 & 71.39 & 94.46 & -0.41 \\
$\boldsymbol{W s}$ & 2.65 & 0.66 & 0.25 & 0.61 & 1.33 & 4.98 & 0.04 \\
$\boldsymbol{E}_{\boldsymbol{P}}$ & 5.00 & 1.59 & 0.32 & 0.08 & 1.37 & 9.97 & 1 \\
\hline
\end{tabular}

611 The unit of $R g, T a, P a$, Wsand $E_{P}$ are $\mathrm{MJ} \mathrm{m}^{-2},{ }^{\circ} \mathrm{C}, \mathrm{hPa}, \mathrm{ms}^{-1}$ and $\mathrm{mm}$, respectively; $\mathrm{x}_{\text {mean }}, \mathrm{S}_{\mathrm{x}}, \mathrm{C}_{\mathrm{v}}, \mathrm{C}_{\mathrm{x}}, \mathrm{x}_{\mathrm{min}}$ and

$612 \mathrm{x}_{\max }$ denote the mean, standard deviation, variation coefficient, skewness, minimum and maximum values, 613 respectively.

614

615

616

617

618

619

620

621

Table 2.The input combinations for different artificial intelligence techniques.

\begin{tabular}{ccccccc}
\hline & \multicolumn{5}{c}{ Models } & Input combinations \\
\cline { 1 - 4 } ANFIS-GP & FG & GRNN & LSSV & MARS & MLP & \\
\hline ANFIS-GP1 & FG1 & GRNN1 & LSSV1 & MARS1 & MLP1 & Rg \\
ANFIS-GP2 & FG2 & GRNN2 & LSSV2 & MARS2 & MLP2 & Ta \\
ANFIS-GP3 & FG3 & GRNN3 & LSSV3 & MARS3 & MLP3 & Hs \\
ANFIS-GP4 & FG4 & GRNN4 & LSSV4 & MARS4 & MLP4 & Rg, Ta \\
ANFIS-GP5 & FG5 & GRNN5 & LSSV5 & MARS5 & MLP5 & $\boldsymbol{R g}, \boldsymbol{T a}, \boldsymbol{H s}$ \\
ANFIS-GP6 & FG6 & GRNN6 & LSSV6 & MARS6 & MLP6 & $\boldsymbol{R g}, \boldsymbol{T a}, \boldsymbol{H s , ~} \boldsymbol{R H}$ \\
ANFIS-GP7 & FG7 & GRNN7 & LSSV7 & MARS7 & MLP7 & $\boldsymbol{R g}, \boldsymbol{T a}, \boldsymbol{H s , ~} \boldsymbol{R H}, \boldsymbol{W s}$ \\
\hline
\end{tabular}

622

623

624

625

626

627

628

629

630

631

632

633

634

635 
Hydrol. Earth Syst. Sci. Discuss., doi:10.5194/hess-2016-247, 2016

Manuscript under review for journal Hydrol. Earth Syst. Sci.

Published: 23 May 2016

(c) Author(s) 2016. CC-BY 3.0 License.

636 Table 3. Comparisons of different models for predicting Ep at HEB.

\begin{tabular}{|c|c|c|c|c|c|c|}
\hline HEB & MAE & RMSE & $\mathrm{R}^{2}$ & MAE & RMSE & $\mathrm{R}^{2}$ \\
\hline ANFIS-GP1 & 1.062 & 1.411 & 0.815 & 1.044 & 1.431 & 0.819 \\
\hline ANFIS-GP2 & 1.226 & 1.68 & 0.737 & 1.082 & 1.471 & 0.797 \\
\hline ANFIS-GP3 & 1.589 & 2.05 & 0.609 & 1.496 & 1.834 & 0.726 \\
\hline ANFIS-GP4 & 0.865 & 1.225 & 0.86 & 0.781 & 1.089 & 0.894 \\
\hline ANFIS-GP5 & 0.785 & 1.167 & 0.873 & 0.645 & 0.907 & 0.923 \\
\hline ANFIS-GP6 & 0.429 & 0.601 & 0.966 & 0.517 & 0.751 & 0.956 \\
\hline ANFIS-GP7 & 0.378 & 0.521 & 0.975 & 0.431 & 0.6 & 0.967 \\
\hline FG1 & 1.031 & 1.371 & 0.825 & 1.031 & 1.507 & 0.816 \\
\hline FG2 & 1.151 & 1.632 & 0.752 & 1.077 & 1.502 & 0.786 \\
\hline FG3 & 1.528 & 2.008 & 0.625 & 1.354 & 1.798 & 0.74 \\
\hline FG4 & 0.719 & 1.071 & 0.893 & 0.688 & 1.178 & 0.891 \\
\hline FG5 & 0.67 & 1.002 & 0.907 & 0.673 & 1.059 & 0.897 \\
\hline FG6 & 0.39 & 0.56 & 0.971 & 0.474 & 0.69 & 0.961 \\
\hline FG7 & 0.305 & 0.421 & 0.983 & 0.435 & 0.661 & 0.959 \\
\hline GRNN1 & 1.057 & 1.428 & 0.819 & 1.039 & 1.403 & 0.817 \\
\hline GRNN2 & 1.155 & 1.632 & 0.753 & 1.057 & 1.475 & 0.796 \\
\hline GRNN3 & 1.519 & 2 & 0.628 & 1.379 & 1.816 & 0.738 \\
\hline GRNN4 & 0.729 & 1.089 & 0.892 & 0.733 & 1.116 & 0.886 \\
\hline GRNN5 & 0.703 & 1.042 & 0.901 & 0.652 & 0.988 & 0.908 \\
\hline GRNN6 & 0.405 & 0.579 & 0.97 & 0.492 & 0.785 & 0.943 \\
\hline GRNN7 & 0.343 & 0.483 & 0.979 & 0.499 & 0.745 & 0.951 \\
\hline LSSV1 & 1.035 & 1.375 & 0.824 & 1.025 & 1.426 & 0.82 \\
\hline LSSV2 & 1.131 & 1.619 & 0.756 & 1.062 & 1.491 & 0.79 \\
\hline LSSV3 & 1.685 & 2.135 & 0.604 & 1.557 & 1.951 & 0.712 \\
\hline LSSV4 & 0.675 & 1.007 & 0.906 & 0.703 & 1.099 & 0.89 \\
\hline LSSV5 & 0.901 & 1.267 & 0.853 & 0.761 & 1.031 & 0.9 \\
\hline LSSV6 & 0.556 & 0.812 & 0.941 & 0.591 & 0.864 & 0.934 \\
\hline LSSV7 & 0.808 & 1.092 & 0.901 & 0.84 & 1.082 & 0.903 \\
\hline MARS1 & 1.038 & 1.371 & 0.825 & 1.064 & 1.581 & 0.805 \\
\hline MARS2 & 1.067 & 1.523 & 0.784 & 1.098 & 1.584 & 0.767 \\
\hline MARS3 & 1.537 & 2.01 & 0.624 & 1.369 & 1.795 & 0.744 \\
\hline MARS4 & 0.659 & 0.972 & 0.912 & 0.806 & 1.39 & 0.861 \\
\hline MARS5 & 0.659 & 0.972 & 0.912 & 0.806 & 1.39 & 0.861 \\
\hline MARS6 & 0.548 & 0.72 & 0.952 & 0.596 & 0.959 & 0.931 \\
\hline MARS7 & 0.507 & 0.641 & 0.962 & 0.581 & 0.763 & 0.949 \\
\hline MLP1 & 1.044 & 1.374 & 0.824 & 1.03 & 1.483 & 0.818 \\
\hline MLP2 & 1.082 & 1.567 & 0.771 & 1.03 & 1.49 & 0.792 \\
\hline MLP3 & 1.135 & 1.618 & 0.757 & 1.04 & 1.46 & 0.798 \\
\hline MLP4 & 0.655 & 0.963 & 0.914 & 0.716 & 1.148 & 0.892 \\
\hline MLP5 & 0.608 & 0.908 & 0.923 & 0.584 & 0.879 & 0.928 \\
\hline MLP6 & 0.314 & 0.458 & 0.98 & 0.409 & 0.607 & 0.97 \\
\hline MLP7 & 0.279 & 0.398 & 0.985 & 0.314 & 0.405 & 0.988 \\
\hline SS & 0.954 & 1.327 & 0.838 & 0.822 & 1.152 & 0.886 \\
\hline MLR & 0.825 & 1.05 & 0.897 & 0.874 & 1.16 & 0.875 \\
\hline
\end{tabular}

637 
Hydrol. Earth Syst. Sci. Discuss., doi:10.5194/hess-2016-247, 2016

Manuscript under review for journal Hydrol. Earth Syst. Sci.

Published: 23 May 2016

(c) Author(s) 2016. CC-BY 3.0 License.

638 Table 4. Comparisons of different models for predicting Ep at ALT.

\begin{tabular}{|c|c|c|c|c|c|c|}
\hline ALT & MAE & RMSE & $\mathrm{R}^{2}$ & MAE & RMSE & $\mathrm{R}^{2}$ \\
\hline ANFIS-GP1 & 1.19 & 1.597 & 0.841 & 1.003 & 1.268 & 0.896 \\
\hline ANFIS-GP2 & 1.19 & 1.506 & 0.859 & 1.11 & 1.435 & 0.884 \\
\hline ANFIS-GP3 & 1.345 & 1.763 & 0.807 & 1.214 & 1.601 & 0.844 \\
\hline ANFIS-GP4 & 0.535 & 0.786 & 0.962 & 0.707 & 1.013 & 0.973 \\
\hline ANFIS-GP5 & 0.494 & 0.737 & 0.966 & 0.691 & 1.012 & 0.977 \\
\hline ANFIS-GP6 & 0.286 & 0.411 & 0.99 & 0.398 & 0.586 & 0.984 \\
\hline ANFIS-GP7 & 0.241 & 0.351 & 0.992 & 0.371 & 0.545 & 0.987 \\
\hline FG1 & 1.079 & 1.398 & 0.878 & 0.994 & 1.3 & 0.891 \\
\hline FG2 & 0.78 & 1.065 & 0.929 & 0.953 & 1.29 & 0.928 \\
\hline FG3 & 1.052 & 1.375 & 0.882 & 1.002 & 1.328 & 0.92 \\
\hline FG4 & 0.45 & 0.703 & 0.969 & 0.67 & 1.027 & 0.971 \\
\hline FG5 & 0.49 & 0.717 & 0.968 & 0.697 & 1.043 & 0.971 \\
\hline FG6 & 0.266 & 0.38 & 0.991 & 0.391 & 0.575 & 0.987 \\
\hline FG7 & 0.253 & 0.343 & 0.993 & 0.394 & 0.57 & 0.988 \\
\hline GRNN1 & 1.172 & 1.516 & 0.865 & 0.881 & 1.113 & 0.906 \\
\hline GRNN2 & 0.875 & 1.223 & 0.913 & 0.882 & 1.187 & 0.927 \\
\hline GRNN3 & 1.173 & 1.552 & 0.868 & 0.885 & 1.213 & 0.91 \\
\hline GRNN4 & 0.532 & 0.84 & 0.957 & 0.663 & 0.936 & 0.977 \\
\hline GRNN5 & 0.527 & 0.809 & 0.96 & 0.69 & 0.952 & 0.982 \\
\hline GRNN6 & 0.192 & 0.301 & 0.994 & 0.47 & 0.657 & 0.989 \\
\hline GRNN7 & 0.158 & 0.251 & 0.996 & 0.476 & 0.679 & 0.986 \\
\hline LSSV1 & 1.077 & 1.421 & 0.875 & 0.928 & 1.212 & 0.9 \\
\hline LSSV2 & 0.776 & 1.058 & 0.93 & 0.957 & 1.294 & 0.927 \\
\hline LSSV3 & 1.063 & 1.381 & 0.881 & 0.986 & 1.299 & 0.92 \\
\hline LSSV4 & 0.514 & 0.763 & 0.964 & 0.669 & 0.957 & 0.973 \\
\hline LSSV5 & 0.481 & 0.732 & 0.967 & 0.669 & 0.974 & 0.978 \\
\hline LSSV6 & 0.303 & 0.435 & 0.989 & 0.369 & 0.528 & 0.987 \\
\hline LSSV7 & 0.39 & 0.587 & 0.98 & 0.487 & 0.647 & 0.986 \\
\hline MARS1 & 1.032 & 1.371 & 0.883 & 0.956 & 1.269 & 0.899 \\
\hline MARS2 & 0.748 & 1.029 & 0.934 & 0.927 & 1.28 & 0.929 \\
\hline MARS3 & 1.043 & 1.356 & 0.886 & 1.043 & 1.367 & 0.916 \\
\hline MARS4 & 0.437 & 0.657 & 0.973 & 0.641 & 0.996 & 0.975 \\
\hline MARS5 & 0.438 & 0.658 & 0.973 & 0.644 & 1.0 & 0.975 \\
\hline MARS6 & 0.29 & 0.411 & 0.989 & 0.428 & 0.655 & 0.985 \\
\hline MARS7 & 0.276 & 0.382 & 0.991 & 0.403 & 0.622 & 0.987 \\
\hline MLP1 & 1.03 & 1.363 & 0.884 & 0.951 & 1.268 & 0.897 \\
\hline MLP2 & 0.787 & 1.07 & 0.929 & 0.951 & 1.282 & 0.93 \\
\hline MLP3 & 0.752 & 1.039 & 0.933 & 0.93 & 1.28 & 0.929 \\
\hline MLP4 & 0.445 & 0.689 & 0.97 & 0.667 & 1.033 & 0.971 \\
\hline MLP5 & 0.521 & 0.769 & 0.963 & 0.659 & 1.017 & 0.974 \\
\hline MLP6 & 0.234 & 0.34 & 0.993 & 0.348 & 0.523 & 0.989 \\
\hline MLP7 & 0.161 & 0.211 & 0.989 & 0.19 & 0.265 & 0.989 \\
\hline SS & 0.539 & 0.761 & 0.964 & 0.681 & 1.053 & 0.963 \\
\hline MLR & 0.712 & 0.89 & 0.951 & 0.74 & 0.861 & 0.969 \\
\hline
\end{tabular}


Hydrol. Earth Syst. Sci. Discuss., doi:10.5194/hess-2016-247, 2016

Manuscript under review for journal Hydrol. Earth Syst. Sci.

Published: 23 May 2016

(c) Author(s) 2016. CC-BY 3.0 License.

640 Table 5. Comparisons of different models for predicting Ep at MQ.

\begin{tabular}{|c|c|c|c|c|c|c|}
\hline MQ & MAE & RMSE & $\mathrm{R}^{2}$ & MAE & RMSE & $\mathrm{R}^{2}$ \\
\hline ANFIS-GP1 & 1.337 & 1.76 & 0.85 & 1.133 & 1.396 & 0.941 \\
\hline ANFIS-GP2 & 1.33 & 1.698 & 0.86 & 1.203 & 1.587 & 0.863 \\
\hline ANFIS-GP3 & 2.467 & 3.11 & 0.53 & 2.453 & 3.045 & 0.55 \\
\hline ANFIS-GP4 & 0.83 & 1.178 & 0.933 & 0.868 & 1.22 & 0.952 \\
\hline ANFIS-GP5 & 0.828 & 1.165 & 0.828 & 0.882 & 1.229 & 0.951 \\
\hline ANFIS-GP6 & 0.648 & 0.886 & 0.962 & 0.608 & 0.81 & 0.981 \\
\hline ANFIS-GP7 & 0.474 & 0.66 & 0.979 & 0.512 & 0.646 & 0.987 \\
\hline FG1 & 1.297 & 1.735 & 0.854 & 1.112 & 1.412 & 0.926 \\
\hline FG2 & 1.263 & 1.638 & 0.87 & 1.198 & 1.555 & 0.87 \\
\hline FG3 & 2.447 & 3.057 & 0.546 & 2.373 & 2.953 & 0.58 \\
\hline FG4 & 0.828 & 1.178 & 0.933 & 0.854 & 1.196 & 0.952 \\
\hline FG5 & 0.795 & 1.13 & 0.938 & 0.923 & 1.335 & 0.942 \\
\hline FG6 & 0.608 & 0.81 & 0.968 & 0.636 & 0.805 & 0.978 \\
\hline FG7 & 0.456 & 0.614 & 0.983 & 0.435 & 0.574 & 0.99 \\
\hline GRNN1 & 1.427 & 1.814 & 0.854 & 1.071 & 1.315 & 0.925 \\
\hline GRNN2 & 1.225 & 1.593 & 0.877 & 1.148 & 1.504 & 0.876 \\
\hline GRNN3 & 2.663 & 3.15 & 0.542 & 2.381 & 2.821 & 0.596 \\
\hline GRNN4 & 0.733 & 1.056 & 0.946 & 0.78 & 1.089 & 0.954 \\
\hline GRNN5 & 0.647 & 0.944 & 0.957 & 0.815 & 1.161 & 0.951 \\
\hline GRNN6 & 0.329 & 0.486 & 0.989 & 0.634 & 0.892 & 0.972 \\
\hline GRNN7 & 0.248 & 0.392 & 0.993 & 0.548 & 0.74 & 0.981 \\
\hline LSSV1 & 1.343 & 1.758 & 0.85 & 1.094 & 1.368 & 0.935 \\
\hline LSSV2 & 1.274 & 1.643 & 0.869 & 1.187 & 1.548 & 0.869 \\
\hline LSSV3 & 2.46 & 3.057 & 0.547 & 2.383 & 2.942 & 0.574 \\
\hline LSSV4 & 1.06 & 1.365 & 0.925 & 0.93 & 1.107 & 0.951 \\
\hline LSSV5 & 0.815 & 1.143 & 0.937 & 0.9 & 1.225 & 0.945 \\
\hline LSSV6 & 0.934 & 1.193 & 0.94 & 0.891 & 1.089 & 0.962 \\
\hline LSSV7 & 0.888 & 1.113 & 0.95 & 0.767 & 0.927 & 0.97 \\
\hline MARS1 & 1.291 & 1.728 & 0.855 & 1.092 & 1.404 & 0.928 \\
\hline MARS2 & 1.076 & 1.462 & 0.896 & 1.078 & 1.471 & 0.888 \\
\hline MARS3 & 2.419 & 3.039 & 0.552 & 2.436 & 2.996 & 0.564 \\
\hline MARS4 & 0.815 & 1.144 & 0.936 & 0.922 & 1.23 & 0.947 \\
\hline MARS5 & 0.807 & 1.126 & 0.938 & 0.97 & 1.29 & 0.95 \\
\hline MARS6 & 0.668 & 0.87 & 0.963 & 0.735 & 0.929 & 0.973 \\
\hline MARS7 & 0.546 & 0.72 & 0.975 & 0.627 & 0.826 & 0.977 \\
\hline MLP1 & 1.297 & 1.735 & 0.854 & 1.107 & 1.408 & 0.928 \\
\hline MLP2 & 1.057 & 1.458 & 0.897 & 1.113 & 1.492 & 0.888 \\
\hline MLP3 & 1.139 & 1.524 & 0.887 & 1.108 & 1.488 & 0.884 \\
\hline MLP4 & 0.724 & 1.026 & 0.949 & 0.797 & 1.074 & 0.96 \\
\hline MLP5 & 0.742 & 1.064 & 0.945 & 0.821 & 1.113 & 0.959 \\
\hline MLP6 & 0.538 & 0.738 & 0.974 & 0.538 & 0.716 & 0.981 \\
\hline MLP7 & 0.384 & 0.532 & 0.986 & 0.358 & 0.489 & 0.99 \\
\hline SS & 0.922 & 1.281 & 0.92 & 1.039 & 1.389 & 0.944 \\
\hline MLR & 0.77 & 0.967 & 0.955 & 0.784 & 0.921 & 0.972 \\
\hline
\end{tabular}


Hydrol. Earth Syst. Sci. Discuss., doi:10.5194/hess-2016-247, 2016

Manuscript under review for journal Hydrol. Earth Syst. Sci.

Published: 23 May 2016

(c) Author(s) 2016. CC-BY 3.0 License.

642 Table 6. Comparisons of different models for predicting Ep at BJ.

\begin{tabular}{|c|c|c|c|c|c|c|}
\hline $\mathrm{BJ}$ & MAE & RMSE & $\mathrm{R}^{2}$ & MAE & RMSE & $\mathrm{R}^{2}$ \\
\hline ANFIS-GP1 & 0.872 & 1.205 & 0.826 & 0.749 & 0.956 & 0.922 \\
\hline ANFIS-GP2 & 1.439 & 1.907 & 0.564 & 1.294 & 1.554 & 0.662 \\
\hline ANFIS-GP3 & 1.431 & 1.818 & 0.603 & 1.482 & 1.88 & 0.561 \\
\hline ANFIS-GP4 & 0.846 & 1.189 & 0.831 & 0.717 & 0.923 & 0.921 \\
\hline ANFIS-GP5 & 0.742 & 1.071 & 0.862 & 0.688 & 0.972 & 0.909 \\
\hline ANFIS-GP6 & 0.464 & 0.735 & 0.935 & 0.384 & 0.51 & 0.965 \\
\hline ANFIS-GP7 & 0.424 & 0.657 & 0.948 & 0.361 & 0.48 & 0.971 \\
\hline FG1 & 0.835 & 1.127 & 0.848 & 0.823 & 1.075 & 0.914 \\
\hline FG2 & 1.416 & 1.891 & 0.571 & 1.256 & 1.544 & 0.665 \\
\hline FG3 & 1.387 & 1.733 & 0.64 & 1.483 & 1.846 & 0.561 \\
\hline FG4 & 0.742 & 1.063 & 0.864 & 0.688 & 0.997 & 0.922 \\
\hline FG5 & 0.721 & 1.052 & 0.867 & 0.679 & 0.959 & 0.926 \\
\hline FG6 & 0.451 & 0.721 & 0.938 & 0.394 & 0.484 & 0.971 \\
\hline FG7 & 0.431 & 0.655 & 0.949 & 0.431 & 0.586 & 0.963 \\
\hline GRNN1 & 0.819 & 1.114 & 0.852 & 0.811 & 1.062 & 0.916 \\
\hline GRNN2 & 1.379 & 1.852 & 0.589 & 1.23 & 1.52 & 0.678 \\
\hline GRNN3 & 1.374 & 1.727 & 0.647 & 1.491 & 1.843 & 0.564 \\
\hline GRNN4 & 0.626 & 0.924 & 0.898 & 0.657 & 0.939 & 0.904 \\
\hline GRNN5 & 0.665 & 0.998 & 0.882 & 0.639 & 0.947 & 0.914 \\
\hline GRNN6 & 0.32 & 0.533 & 0.966 & 0.391 & 0.513 & 0.962 \\
\hline GRNN7 & 0.166 & 0.301 & 0.989 & 0.356 & 0.473 & 0.968 \\
\hline LSSV1 & 0.842 & 1.139 & 0.845 & 0.824 & 1.062 & 0.911 \\
\hline LSSV2 & 1.519 & 1.986 & 0.552 & 1.441 & 1.658 & 0.647 \\
\hline LSSV3 & 1.386 & 1.734 & 0.64 & 1.483 & 1.841 & 0.562 \\
\hline LSSV4 & 0.743 & 1.069 & 0.864 & 0.69 & 0.977 & 0.922 \\
\hline LSSV5 & 0.823 & 1.184 & 0.839 & 0.692 & 0.958 & 0.911 \\
\hline LSSV6 & 0.736 & 1.078 & 0.875 & 0.622 & 0.827 & 0.925 \\
\hline LSSV7 & 0.486 & 0.76 & 0.933 & 0.338 & 0.444 & 0.973 \\
\hline MARS1 & 0.829 & 1.118 & 0.85 & 0.854 & 1.071 & 0.915 \\
\hline MARS2 & 1.364 & 1.832 & 0.597 & 1.282 & 1.607 & 0.659 \\
\hline MARS3 & 1.355 & 1.717 & 0.647 & 1.477 & 1.846 & 0.565 \\
\hline MARS4 & 0.705 & 0.979 & 0.885 & 0.68 & 0.976 & 0.909 \\
\hline MARS5 & 0.687 & 0.972 & 0.887 & 0.687 & 0.991 & 0.903 \\
\hline MARS6 & 0.52 & 0.767 & 0.929 & 0.5 & 0.603 & 0.963 \\
\hline MARS7 & 0.478 & 0.717 & 0.938 & 0.427 & 0.527 & 0.971 \\
\hline MLP1 & 0.784 & 1.075 & 0.861 & 0.813 & 1.045 & 0.914 \\
\hline MLP2 & 1.325 & 1.803 & 0.61 & 1.249 & 1.595 & 0.677 \\
\hline MLP3 & 1.401 & 1.875 & 0.578 & 1.236 & 1.523 & 0.678 \\
\hline MLP4 & 0.675 & 0.968 & 0.888 & 0.66 & 0.974 & 0.911 \\
\hline MLP5 & 0.653 & 0.962 & 0.889 & 0.62 & 0.907 & 0.904 \\
\hline MLP6 & 0.417 & 0.692 & 0.943 & 0.312 & 0.394 & 0.982 \\
\hline MLP7 & 0.337 & 0.506 & 0.969 & 0.314 & 0.428 & 0.979 \\
\hline SS & 0.89 & 1.263 & 0.816 & 0.647 & 0.921 & 0.897 \\
\hline MLR & 0.614 & 0.879 & 0.907 & 0.514 & 0.648 & 0.946 \\
\hline
\end{tabular}


Hydrol. Earth Syst. Sci. Discuss., doi:10.5194/hess-2016-247, 2016

Manuscript under review for journal Hydrol. Earth Syst. Sci.

Published: 23 May 2016

(c) Author(s) 2016. CC-BY 3.0 License.

644 Table 7. Comparisons of different models for predicting Ep at LSA.

\begin{tabular}{|c|c|c|c|c|c|c|}
\hline LSA & MAE & RMSE & $\mathrm{R}^{2}$ & MAE & RMSE & $\mathrm{R}^{2}$ \\
\hline ANFIS-GP1 & 1.327 & 1.718 & 0.411 & 1.072 & 1.424 & 0.594 \\
\hline ANFIS-GP2 & 1.245 & 1.523 & 0.536 & 1.192 & 1.417 & 0.601 \\
\hline ANFIS-GP3 & 1.821 & 2.218 & 0.017 & 1.796 & 2.148 & 0.055 \\
\hline ANFIS-GP4 & 1.149 & 1.471 & 0.568 & 1.046 & 1.304 & 0.651 \\
\hline ANFIS-GP5 & 0.966 & 1.223 & 0.701 & 0.875 & 1.082 & 0.761 \\
\hline ANFIS-GP6 & 0.529 & 0.675 & 0.909 & 0.73 & 0.907 & 0.896 \\
\hline ANFIS-GP7 & 0.478 & 0.61 & 0.926 & 0.816 & 1.038 & 0.875 \\
\hline FG1 & 1.324 & 1.715 & 0.413 & 1.073 & 1.415 & 0.6 \\
\hline FG2 & 1.151 & 1.465 & 0.571 & 1.159 & 1.392 & 0.621 \\
\hline FG3 & 1.803 & 2.169 & 0.06 & 1.771 & 2.093 & 0.118 \\
\hline FG4 & 1.044 & 1.381 & 0.619 & 0.987 & 1.201 & 0.725 \\
\hline FG5 & 0.968 & 1.215 & 0.705 & 0.896 & 1.099 & 0.757 \\
\hline FG6 & 0.499 & 0.631 & 0.921 & 0.767 & 0.925 & 0.903 \\
\hline FG7 & 0.491 & 0.61 & 0.926 & 0.729 & 0.886 & 0.914 \\
\hline GRNN1 & 1.296 & 1.692 & 0.429 & 1.094 & 1.436 & 0.587 \\
\hline GRNN2 & 1.025 & 1.336 & 0.647 & 1.072 & 1.288 & 0.679 \\
\hline GRNN3 & 1.783 & 2.152 & 0.077 & 1.762 & 2.08 & 0.134 \\
\hline GRNN4 & 0.841 & 1.131 & 0.751 & 0.817 & 1.032 & 0.795 \\
\hline GRNN5 & 0.639 & 0.844 & 0.862 & 0.714 & 0.937 & 0.828 \\
\hline GRNN6 & 0.33 & 0.427 & 0.965 & 0.533 & 0.65 & 0.926 \\
\hline GRNN7 & 0.326 & 0.417 & 0.967 & 0.459 & 0.592 & 0.933 \\
\hline LSSV1 & 1.376 & 1.754 & 0.41 & 1.211 & 1.508 & 0.599 \\
\hline LSSV2 & 1.22 & 1.499 & 0.554 & 1.213 & 1.422 & 0.606 \\
\hline LSSV3 & 1.811 & 2.209 & 0.027 & 1.791 & 2.144 & 0.07 \\
\hline LSSV4 & 1.163 & 1.476 & 0.573 & 1.078 & 1.31 & 0.663 \\
\hline LSSV5 & 0.987 & 1.253 & 0.69 & 0.894 & 1.085 & 0.777 \\
\hline LSSV6 & 0.462 & 0.601 & 0.933 & 0.646 & 0.799 & 0.916 \\
\hline LSSV7 & 0.47 & 0.609 & 0.932 & 0.591 & 0.713 & 0.928 \\
\hline MARS1 & 1.316 & 1.713 & 0.414 & 1.072 & 1.412 & 0.602 \\
\hline MARS2 & 1.012 & 1.318 & 0.653 & 1.098 & 1.299 & 0.683 \\
\hline MARS3 & 1.82 & 2.182 & 0.049 & 1.766 & 2.089 & 0.12 \\
\hline MARS4 & 0.917 & 1.23 & 0.698 & 0.947 & 1.176 & 0.735 \\
\hline MARS5 & 0.94 & 1.227 & 0.699 & 0.913 & 1.135 & 0.746 \\
\hline MARS6 & 0.501 & 0.641 & 0.918 & 0.762 & 0.929 & 0.91 \\
\hline MARS7 & 0.528 & 0.66 & 0.913 & 0.697 & 0.85 & 0.92 \\
\hline MLP1 & 1.308 & 1.707 & 0.418 & 1.073 & 1.413 & 0.596 \\
\hline MLP2 & 0.992 & 1.307 & 0.659 & 1.111 & 1.313 & 0.675 \\
\hline MLP3 & 0.994 & 1.316 & 0.654 & 1.108 & 1.312 & 0.675 \\
\hline MLP4 & 0.883 & 1.187 & 0.719 & 0.918 & 1.123 & 0.754 \\
\hline MLP5 & 0.686 & 0.91 & 0.835 & 0.728 & 0.958 & 0.825 \\
\hline MLP6 & 0.397 & 0.503 & 0.949 & 0.629 & 0.771 & 0.928 \\
\hline MLP7 & 0.522 & 0.681 & 0.907 & 0.53 & 0.638 & 0.936 \\
\hline SS & 1.198 & 1.577 & 0.515 & 0.969 & 1.307 & 0.652 \\
\hline MLR & 0.628 & 0.795 & 0.874 & 0.656 & 0.789 & 0.906 \\
\hline
\end{tabular}


Hydrol. Earth Syst. Sci. Discuss., doi:10.5194/hess-2016-247, 2016

Manuscript under review for journal Hydrol. Earth Syst. Sci.

Published: 23 May 2016

(c) Author(s) 2016. CC-BY 3.0 License.

646 Table 8. Comparisons of different models for predicting Ep at CQ.

\begin{tabular}{|c|c|c|c|c|c|c|}
\hline CQ & MAE & RMSE & $\mathrm{R}^{2}$ & MAE & RMSE & $\mathrm{R}^{2}$ \\
\hline ANFIS-GP1 & 0.466 & 0.859 & 0.815 & 0.28 & 0.397 & 0.958 \\
\hline ANFIS-GP2 & 0.82 & 1.189 & 0.645 & 0.693 & 0.959 & 0.748 \\
\hline ANFIS-GP3 & 0.539 & 0.722 & 0.869 & 0.537 & 0.679 & 0.876 \\
\hline ANFIS-GP4 & 0.416 & 0.786 & 0.845 & 0.316 & 0.398 & 0.959 \\
\hline ANFIS-GP5 & 0.369 & 0.492 & 0.939 & 0.242 & 0.329 & 0.968 \\
\hline ANFIS-GP6 & 0.225 & 0.29 & 0.979 & 0.224 & 0.312 & 0.976 \\
\hline ANFIS-GP7 & 0.187 & 0.244 & 0.985 & 0.203 & 0.3 & 0.978 \\
\hline FG1 & 0.467 & 0.805 & 0.837 & 0.294 & 0.375 & 0.963 \\
\hline FG2 & 0.611 & 0.881 & 0.805 & 0.571 & 0.691 & 0.873 \\
\hline FG3 & 0.474 & 0.672 & 0.887 & 0.479 & 0.607 & 0.905 \\
\hline FG4 & 0.385 & 0.704 & 0.876 & 0.303 & 0.384 & 0.96 \\
\hline FG5 & 0.297 & 0.402 & 0.959 & 0.273 & 0.19 & 0.944 \\
\hline FG6 & 0.275 & 0.359 & 0.968 & 0.3 & 0.407 & 0.955 \\
\hline FG7 & 0.195 & 0.25 & 0.984 & 0.182 & 0.28 & 0.981 \\
\hline GRNN1 & 0.437 & 0.746 & 0.861 & 0.284 & 0.374 & 0.963 \\
\hline GRNN2 & 0.574 & 0.845 & 0.823 & 0.507 & 0.651 & 0.883 \\
\hline GRNN3 & 0.453 & 0.652 & 0.893 & 0.473 & 0.61 & 0.902 \\
\hline GRNN4 & 0.328 & 0.645 & 0.897 & 0.285 & 0.37 & 0.962 \\
\hline GRNN5 & 0.221 & 0.308 & 0.976 & 0.24 & 0.327 & 0.968 \\
\hline GRNN6 & 0.145 & 0.203 & 0.99 & 0.177 & 0.24 & 0.983 \\
\hline GRNN7 & 0.227 & 0.308 & 0.977 & 0.234 & 0.297 & 0.975 \\
\hline LSSV1 & 0.714 & 1.028 & 0.81 & 0.6 & 0.734 & 0.961 \\
\hline LSSV2 & 0.552 & 0.825 & 0.829 & 0.503 & 0.65 & 0.888 \\
\hline LSSV3 & 0.687 & 0.862 & 0.887 & 0.625 & 0.765 & 0.906 \\
\hline LSSV4 & 0.543 & 0.873 & 0.833 & 0.449 & 0.58 & 0.94 \\
\hline LSSV5 & 0.336 & 0.48 & 0.942 & 0.292 & 0.372 & 0.959 \\
\hline LSSV6 & 0.314 & 0.496 & 0.94 & 0.219 & 0.284 & 0.977 \\
\hline LSSV7 & 0.317 & 0.49 & 0.942 & 0.22 & 0.292 & 0.976 \\
\hline MARS1 & 0.451 & 0.709 & 0.874 & 0.28 & 0.441 & 0.943 \\
\hline MARS2 & 0.555 & 0.822 & 0.83 & 0.498 & 0.651 & 0.889 \\
\hline MARS3 & 0.453 & 0.664 & 0.889 & 0.466 & 0.599 & 0.904 \\
\hline MARS4 & 0.363 & 0.624 & 0.902 & 0.33 & 0.441 & 0.95 \\
\hline MARS5 & 0.336 & 0.48 & 0.942 & 0.292 & 0.372 & 0.959 \\
\hline MARS6 & 0.273 & 0.426 & 0.954 & 0.219 & 0.299 & 0.974 \\
\hline MARS7 & 0.267 & 0.417 & 0.956 & 0.25 & 0.323 & 0.956 \\
\hline MLP1 & 0.419 & 0.733 & 0.865 & 0.27 & 0.371 & 0.96 \\
\hline MLP2 & 0.55 & 0.81 & 0.835 & 0.509 & 0.658 & 0.887 \\
\hline MLP3 & 0.568 & 0.845 & 0.82 & 0.502 & 0.637 & 0.893 \\
\hline MLP4 & 0.334 & 0.65 & 0.894 & 0.266 & 0.355 & 0.966 \\
\hline MLP5 & 0.252 & 0.348 & 0.97 & 0.218 & 0.296 & 0.975 \\
\hline MLP6 & 0.185 & 0.239 & 0.986 & 0.167 & 0.23 & 0.985 \\
\hline MLP7 & 0.161 & 0.211 & 0.989 & 0.189 & 0.265 & 0.985 \\
\hline SS & 0.379 & 0.786 & 0.847 & 0.226 & 0.307 & 0.973 \\
\hline MLR & 0.389 & 0.534 & 0.928 & 0.317 & 0.398 & 0.955 \\
\hline
\end{tabular}


Hydrol. Earth Syst. Sci. Discuss., doi:10.5194/hess-2016-247, 2016

Manuscript under review for journal Hydrol. Earth Syst. Sci.

Published: 23 May 2016

(c) Author(s) 2016. CC-BY 3.0 License.

648 Table 9. Comparisons of different models for predicting Ep at HZ station.

\begin{tabular}{|c|c|c|c|c|c|c|}
\hline & MAE & RMSE & $\mathrm{R}^{2}$ & MAE & RMSE & $\mathrm{R}^{2}$ \\
\hline ANFIS-GP1 & 0.532 & 0.698 & 0.87 & 0.451 & 0.605 & 0.903 \\
\hline ANFIS-GP2 & 0.72 & 1.001 & 0.734 & 0.728 & 0.965 & 0.754 \\
\hline ANFIS-GP3 & 0.937 & 1.164 & 0.64 & 0.991 & 1.178 & 0.694 \\
\hline ANFIS-GP4 & 0.377 & 0.521 & 0.928 & 0.333 & 0.448 & 0.948 \\
\hline ANFIS-GP5 & 0.357 & 0.482 & 0.938 & 0.311 & 0.397 & 0.961 \\
\hline ANFIS-GP6 & 0.272 & 0.356 & 0.966 & 0.329 & 0.427 & 0.965 \\
\hline ANFIS-GP7 & 0.242 & 0.312 & 0.974 & 0.347 & 0.453 & 0.949 \\
\hline FG1 & 0.519 & 0.686 & 0.875 & 0.438 & 0.59 & 0.908 \\
\hline FG2 & 0.62 & 0.817 & 0.822 & 0.626 & 0.786 & 0.837 \\
\hline FG3 & 0.943 & 1.151 & 0.648 & 1.01 & 1.188 & 0.699 \\
\hline FG4 & 0.358 & 0.485 & 0.938 & 0.299 & 0.397 & 0.959 \\
\hline FG5 & 0.344 & 0.462 & 0.943 & 0.29 & 0.373 & 0.965 \\
\hline FG6 & 0.269 & 0.347 & 0.968 & 0.295 & 0.375 & 0.974 \\
\hline FG7 & 0.26 & 0.36 & 0.966 & 0.278 & 0.369 & 0.964 \\
\hline GRNN1 & 0.519 & 0.68 & 0.878 & 0.457 & 0.607 & 0.904 \\
\hline GRNN2 & 0.556 & 0.733 & 0.859 & 0.581 & 0.736 & 0.86 \\
\hline GRNN3 & 0.926 & 1.127 & 0.664 & 1.02 & 1.197 & 0.705 \\
\hline GRNN4 & 0.322 & 0.438 & 0.949 & 0.314 & 0.409 & 0.957 \\
\hline GRNN5 & 0.238 & 0.327 & 0.972 & 0.295 & 0.404 & 0.961 \\
\hline GRNN6 & 0.232 & 0.3 & 0.977 & 0.275 & 0.346 & 0.969 \\
\hline GRNN7 & 0.223 & 0.295 & 0.978 & 0.335 & 0.445 & 0.956 \\
\hline LSSV1 & 0.593 & 0.801 & 0.87 & 0.572 & 0.731 & 0.903 \\
\hline LSSV2 & 0.715 & 0.984 & 0.778 & 0.733 & 0.97 & 0.799 \\
\hline LSSV3 & 0.996 & 1.214 & 0.638 & 1.074 & 1.267 & 0.678 \\
\hline LSSV4 & 0.413 & 0.594 & 0.924 & 0.399 & 0.548 & 0.94 \\
\hline LSSV5 & 0.398 & 0.554 & 0.929 & 0.376 & 0.509 & 0.953 \\
\hline LSSV6 & 0.278 & 0.378 & 0.964 & 0.3 & 0.372 & 0.968 \\
\hline LSSV7 & 0.292 & 0.406 & 0.959 & 0.338 & 0.441 & 0.957 \\
\hline MARS1 & 0.52 & 0.69 & 0.874 & 0.443 & 0.601 & 0.904 \\
\hline MARS2 & 0.534 & 0.686 & 0.875 & 0.524 & 0.673 & 0.881 \\
\hline MARS3 & 0.915 & 1.125 & 0.664 & 0.999 & 1.189 & 0.698 \\
\hline MARS4 & 0.339 & 0.449 & 0.946 & 0.273 & 0.362 & 0.966 \\
\hline MARS5 & 0.335 & 0.437 & 0.949 & 0.282 & 0.358 & 0.966 \\
\hline MARS6 & 0.286 & 0.37 & 0.964 & 0.318 & 0.393 & 0.976 \\
\hline MARS7 & 0.27 & 0.358 & 0.966 & 0.276 & 0.361 & 0.967 \\
\hline MLP1 & 0.529 & 0.691 & 0.873 & 0.449 & 0.598 & 0.906 \\
\hline MLP2 & 0.523 & 0.68 & 0.877 & 0.523 & 0.674 & 0.881 \\
\hline MLP3 & 0.908 & 1.124 & 0.664 & 0.992 & 1.181 & 0.698 \\
\hline MLP4 & 0.334 & 0.65 & 0.894 & 0.266 & 0.355 & 0.966 \\
\hline MLP5 & 0.333 & 0.446 & 0.947 & 0.279 & 0.348 & 0.968 \\
\hline MLP6 & 0.247 & 0.326 & 0.972 & 0.318 & 0.405 & 0.978 \\
\hline MLP7 & 0.244 & 0.319 & 0.973 & 0.263 & 0.34 & 0.977 \\
\hline SS & 0.35 & 0.487 & 0.938 & 0.291 & 0.388 & 0.96 \\
\hline MLR & 0.32 & 0.427 & 0.952 & 0.395 & 0.486 & 0.942 \\
\hline
\end{tabular}


Hydrol. Earth Syst. Sci. Discuss., doi:10.5194/hess-2016-247, 2016

Manuscript under review for journal Hydrol. Earth Syst. Sci.

Published: 23 May 2016

(c) Author(s) 2016. CC-BY 3.0 License.

650 Table 10. Comparisons of different models for predicting Ep at HK.

\begin{tabular}{|c|c|c|c|c|c|c|}
\hline $\mathrm{HK}$ & MAE & RMSE & $\mathrm{R}^{2}$ & MAE & RMSE & $\mathrm{R}^{2}$ \\
\hline ANFIS-GP1 & 0.528 & 0.688 & 0.814 & 0.669 & 0.8 & 0.854 \\
\hline ANFIS-GP2 & 0.741 & 0.964 & 0.634 & 0.802 & 0.97 & 0.742 \\
\hline ANFIS-GP3 & 0.619 & 0.798 & 0.749 & 0.482 & 0.61 & 0.851 \\
\hline ANFIS-GP4 & 0.488 & 0.646 & 0.836 & 0.66 & 0.796 & 0.861 \\
\hline ANFIS-GP5 & 0.46 & 0.597 & 0.86 & 0.494 & 0.609 & 0.891 \\
\hline ANFIS-GP6 & 0.388 & 0.501 & 0.901 & 0.809 & 0.93 & 0.919 \\
\hline ANFIS-GP7 & 0.286 & 0.379 & 0.943 & 0.428 & 0.555 & 0.925 \\
\hline FG1 & 0.506 & 0.661 & 0.828 & 0.662 & 0.792 & 0.858 \\
\hline FG2 & 0.716 & 0.914 & 0.671 & 0.793 & 0.94 & 0.784 \\
\hline FG3 & 0.612 & 0.768 & 0.768 & 0.503 & 0.63 & 0.85 \\
\hline FG4 & 0.471 & 0.626 & 0.846 & 0.659 & 0.786 & 0.875 \\
\hline FG5 & 0.451 & 0.591 & 0.863 & 0.485 & 0.596 & 0.895 \\
\hline FG6 & 0.39 & 0.496 & 0.903 & 0.718 & 0.849 & 0.92 \\
\hline FG7 & 0.381 & 0.494 & 0.904 & 0.452 & 0.566 & 0.886 \\
\hline GRNN1 & 0.505 & 0.666 & 0.829 & 0.673 & 0.81 & 0.854 \\
\hline GRNN2 & 0.699 & 0.902 & 0.681 & 0.786 & 0.929 & 0.776 \\
\hline GRNN3 & 0.6 & 0.759 & 0.775 & 0.511 & 0.642 & 0.845 \\
\hline GRNN4 & 0.452 & 0.605 & 0.859 & 0.65 & 0.771 & 0.879 \\
\hline GRNN5 & 0.405 & 0.535 & 0.889 & 0.484 & 0.589 & 0.892 \\
\hline GRNN6 & 0.408 & 0.538 & 0.894 & 0.539 & 0.651 & 0.916 \\
\hline GRNN7 & 0.241 & 0.342 & 0.956 & 0.415 & 0.512 & 0.917 \\
\hline LSSV1 & 0.51 & 0.671 & 0.826 & 0.659 & 0.791 & 0.859 \\
\hline LSSV2 & 0.717 & 0.924 & 0.665 & 0.788 & 0.934 & 0.78 \\
\hline LSSV3 & 0.614 & 0.781 & 0.766 & 0.519 & 0.643 & 0.852 \\
\hline LSSV4 & 0.481 & 0.64 & 0.841 & 0.661 & 0.789 & 0.87 \\
\hline LSSV5 & 0.446 & 0.583 & 0.867 & 0.483 & 0.596 & 0.891 \\
\hline LSSV6 & 0.414 & 0.528 & 0.891 & 0.625 & 0.748 & 0.919 \\
\hline LSSV7 & 0.313 & 0.41 & 0.935 & 0.419 & 0.529 & 0.918 \\
\hline MARS1 & 0.505 & 0.662 & 0.828 & 0.665 & 0.79 & 0.862 \\
\hline MARS2 & 0.664 & 0.862 & 0.708 & 0.858 & 1.023 & 0.766 \\
\hline MARS3 & 0.603 & 0.758 & 0.774 & 0.5 & 0.632 & 0.845 \\
\hline MARS4 & 0.438 & 0.581 & 0.867 & 0.733 & 0.899 & 0.869 \\
\hline MARS5 & 0.426 & 0.547 & 0.882 & 0.536 & 0.691 & 0.891 \\
\hline MARS6 & 0.407 & 0.517 & 0.895 & 0.682 & 0.807 & 0.917 \\
\hline MARS7 & 0.322 & 0.414 & 0.932 & 0.397 & 0.515 & 0.927 \\
\hline MLP1 & 0.512 & 0.671 & 0.823 & 0.657 & 0.793 & 0.855 \\
\hline MLP2 & 0.686 & 0.878 & 0.697 & 0.822 & 0.979 & 0.792 \\
\hline MLP3 & 0.707 & 0.903 & 0.679 & 0.821 & 0.973 & 0.79 \\
\hline MLP4 & 0.47 & 0.623 & 0.847 & 0.657 & 0.779 & 0.878 \\
\hline MLP5 & 0.421 & 0.542 & 0.884 & 0.485 & 0.594 & 0.897 \\
\hline MLP6 & 0.431 & 0.554 & 0.88 & 0.671 & 0.786 & 0.916 \\
\hline MLP7 & 0.34 & 0.444 & 0.923 & 0.386 & 0.491 & 0.930 \\
\hline SS & 0.523 & 0.683 & 0.827 & 0.64 & 0.773 & 0.823 \\
\hline MLR & 0.328 & 0.431 & 0.927 & 0.396 & 0.505 & 0.927 \\
\hline
\end{tabular}


Hydrol. Earth Syst. Sci. Discuss., doi:10.5194/hess-2016-247, 2016

Manuscript under review for journal Hydrol. Earth Syst. Sci.

Published: 23 May 2016

(c) Author(s) 2016. CC-BY 3.0 License.

653

654

655

Table 11. Accuracy ranks of the soft computing models in estimating Ep.

\begin{tabular}{cccccccc}
\hline Stations & ANFIS-GP & FG & GRNN & LSSVR & MARS & MLP & MLR \\
\hline HEB & 2 & 3 & 4 & 6 & 5 & 1 & 7 \\
ALT & 3 & 4 & 6 & 2 & 5 & 1 & 7 \\
MQ & 3 & 2 & 4 & 7 & 5 & 1 & 6 \\
BJ & 4 & 5 & 3 & 2 & 6 & 1 & 7 \\
LSA & 6 & 5 & 1 & 3 & 4 & 2 & 7 \\
CQ & 6 & 3 & 2 & 4 & 5 & 1 & 7 \\
HZ & 6 & 4 & 2 & 5 & 3 & 1 & 7 \\
HK & 6 & 7 & 3 & 5 & 4 & 1 & 2 \\
ALL & 4 & 5 & 2 & 3 & 6 & 1 & 7 \\
\hline Total & $\mathbf{4 0}$ & $\mathbf{3 8}$ & $\mathbf{2 7}$ & $\mathbf{3 7}$ & $\mathbf{4 3}$ & $\mathbf{1 0}$ & $\mathbf{5 7}$ \\
\hline
\end{tabular}

656

657

658

659

660

661

662

663

664

665

666

667

668

669

670

671

672

673

674

675

676

677

678

679

680

681

682

683

684

685

686

687

688

689

690

691

692

693

694 
Hydrol. Earth Syst. Sci. Discuss., doi:10.5194/hess-2016-247, 2016

Manuscript under review for journal Hydrol. Earth Syst. Sci.

Published: 23 May 2016

(c) Author(s) 2016. CC-BY 3.0 License.

Table 12. Comparisons of different models for predicting Ep at all stations.

\begin{tabular}{|c|c|c|c|c|c|c|}
\hline & MAE & RMSE & $\mathrm{R}^{2}$ & MAE & RMSE & $\mathrm{R}^{2}$ \\
\hline ANFIS-GP1 & 1.204 & 1.681 & 0.739 & 1.022 & 1.378 & 0.804 \\
\hline ANFIS-GP2 & 1.906 & 2.522 & 0.412 & 1.768 & 2.345 & 0.437 \\
\hline ANFIS-GP3 & 1.913 & 2.377 & 0.478 & 1.877 & 2.262 & 0.475 \\
\hline ANFIS-GP4 & 0.994 & 1.446 & 0.807 & 0.88 & 1.228 & 0.847 \\
\hline ANFIS-GP5 & 0.917 & 1.341 & 0.834 & 0.782 & 1.113 & 0.872 \\
\hline ANFIS-GP6 & 0.606 & 0.846 & 0.934 & 0.601 & 0.833 & 0.933 \\
\hline ANFIS-GP7 & 0.517 & 0.738 & 0.95 & 0.486 & 0.666 & 0.957 \\
\hline FG1 & 1.208 & 1.676 & 0.74 & 1.028 & 1.377 & 0.805 \\
\hline FG2 & 1.883 & 2.511 & 0.417 & 1.741 & 2.332 & 0.443 \\
\hline FG3 & 1.8 & 2.221 & 0.544 & 1.812 & 2.148 & 0.524 \\
\hline FG4 & 0.936 & 1.378 & 0.824 & 0.821 & 1.154 & 0.865 \\
\hline FG5 & 0.883 & 1.294 & 0.845 & 0.753 & 1.072 & 0.882 \\
\hline FG6 & 0.589 & 0.834 & 0.936 & 0.607 & 0.842 & 0.931 \\
\hline FG7 & 0.518 & 0.744 & 0.949 & 0.495 & 0.678 & 0.956 \\
\hline GRNN1 & 1.193 & 1.669 & 0.743 & 1.013 & 1.373 & 0.806 \\
\hline GRNN2 & 1.859 & 2.49 & 0.427 & 1.716 & 2.311 & 0.453 \\
\hline GRNN3 & 1.772 & 2.216 & 0.549 & 1.773 & 2.127 & 0.532 \\
\hline GRNN4 & 0.819 & 1.234 & 0.86 & 0.733 & 1.075 & 0.884 \\
\hline GRNN5 & 0.724 & 1.114 & 0.886 & 0.642 & 0.963 & 0.905 \\
\hline GRNN6 & 0.458 & 0.674 & 0.958 & 0.489 & 0.723 & 0.947 \\
\hline GRNN7 & 0.265 & 0.425 & 0.984 & 0.364 & 0.573 & 0.967 \\
\hline LSSV1 & 1.198 & 1.667 & 0.743 & 1.017 & 1.371 & 0.807 \\
\hline LSSV2 & 1.85 & 2.495 & 0.425 & 1.703 & 2.312 & 0.453 \\
\hline LSSV3 & 1.854 & 2.314 & 0.506 & 1.858 & 2.215 & 0.493 \\
\hline LSSV4 & 0.935 & 1.386 & 0.823 & 0.806 & 1.149 & 0.866 \\
\hline LSSV5 & 0.933 & 1.369 & 0.827 & 0.8 & 1.134 & 0.867 \\
\hline LSSV6 & 0.824 & 1.148 & 0.879 & 0.774 & 1.023 & 0.893 \\
\hline LSSV7 & 0.494 & 0.719 & 0.952 & 0.476 & 0.657 & 0.958 \\
\hline MARS1 & 1.198 & 1.666 & 0.744 & 1.021 & 1.373 & 0.806 \\
\hline MARS2 & 1.793 & 2.428 & 0.455 & 1.676 & 2.268 & 0.476 \\
\hline MARS3 & 1.782 & 2.209 & 0.549 & 1.788 & 2.131 & 0.532 \\
\hline MARS4 & 1.025 & 1.439 & 0.808 & 0.929 & 1.235 & 0.845 \\
\hline MARS5 & 0.925 & 1.324 & 0.838 & 0.804 & 1.113 & 0.873 \\
\hline MARS6 & 0.783 & 1.032 & 0.902 & 0.76 & 0.963 & 0.909 \\
\hline MARS7 & 0.692 & 0.933 & 0.920 & 0.654 & 0.829 & 0.932 \\
\hline MLP1 & 1.196 & 1.663 & 0.744 & 1.02 & 1.373 & 0.806 \\
\hline MLP2 & 1.835 & 2.485 & 0.429 & 1.689 & 2.304 & 0.457 \\
\hline MLP3 & 1.842 & 2.491 & 0.426 & 1.695 & 2.302 & 0.458 \\
\hline MLP4 & 0.836 & 1.256 & 0.854 & 0.74 & 1.086 & 0.882 \\
\hline MLP5 & 0.774 & 1.181 & 0.871 & 0.649 & 0.98 & 0.902 \\
\hline MLP6 & 0.529 & 0.758 & 0.947 & 0.531 & 0.77 & 0.943 \\
\hline MLP7 & 0.279 & 0.398 & 0.985 & 0.314 & 0.405 & 0.988 \\
\hline SS & 1.107 & 1.544 & 0.785 & 1.007 & 1.336 & 0.823 \\
\hline MLR & 0.905 & 1.235 & 0.859 & 0.86 & 1.091 & 0.88 \\
\hline
\end{tabular}


Hydrol. Earth Syst. Sci. Discuss., doi:10.5194/hess-2016-247, 2016

Manuscript under review for journal Hydrol. Earth Syst. Sci.

Published: 23 May 2016

(c) Author(s) 2016. CC-BY 3.0 License.

698

699

700

701

702

703

704

705

706

707

708

709

710

711

712

713

714

715

716

717

718

719

720

721

722

723

724

725

726

727

728

729

730

731

732

733

734

735

736

737

\section{Figure captions:}

Fig.1. Schematic architecture of: a) MLP neural network; b) GRNN.

Fig.2. Schematic architecture of network-based ANFIS.

Fig.3. The geographical locations of the stations in different climatic zones.

Fig.4. The annual variations of Ep and associated climatic parameters in each station.

Fig.5. Monthly variations of Ep and associated climatic parameters in each station.

Fig.6. Comparison of the observed and estimated Ep using the optimal ANFIS-GP model during the testing period.

Fig.7. Comparison of the observed and estimated Ep using the optimal FG model during the testing period.

Fig.8. Comparison of the observed and estimated Ep using the optimal GRNN model during the testing period.

Fig.9. Comparison of the observed and estimated Ep using the optimal LSSVM model during the testing period.

Fig.10. Comparison of the observed and estimated Ep using the optimal MARS model during the testing period.

Fig.11. Comparison of the observed and estimated Ep using the optimal MLP model during the testing period.

Fig.12. Comparison of the observed and estimated Ep using the optimal SS model during the testing period.

Fig.13. Comparison of the observed and estimated Ep using the optimal MLR model during the testing period. 
Hydrol. Earth Syst. Sci. Discuss., doi:10.5194/hess-2016-247, 2016

Manuscript under review for journal Hydrol. Earth Syst. Sci.

Published: 23 May 2016

(c) Author(s) 2016. CC-BY 3.0 License.

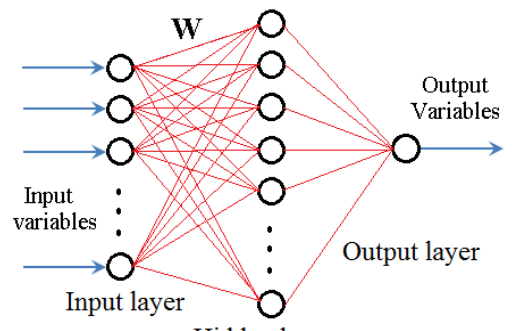

a) Hidden layer

Fig. 1. Schematic architecture of: a) MLP neural network; b) GRNN.

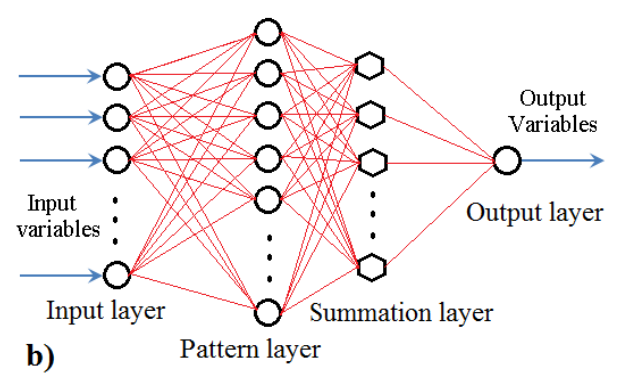

b) 
Hydrol. Earth Syst. Sci. Discuss., doi:10.5194/hess-2016-247, 2016

Manuscript under review for journal Hydrol. Earth Syst. Sci.

Published: 23 May 2016

(c) Author(s) 2016. CC-BY 3.0 License.

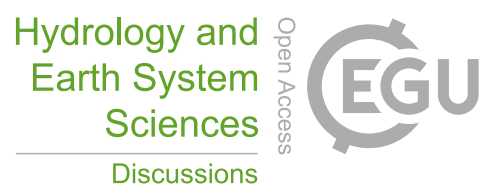

(c) (1)

782

784

785

786

787

788

789

790

791

792

793

794

795

796

797

798

799

800

801

802

803

804

805

806

807

808

809

810

811

812

813

814

815

816

817

818

819

820

821

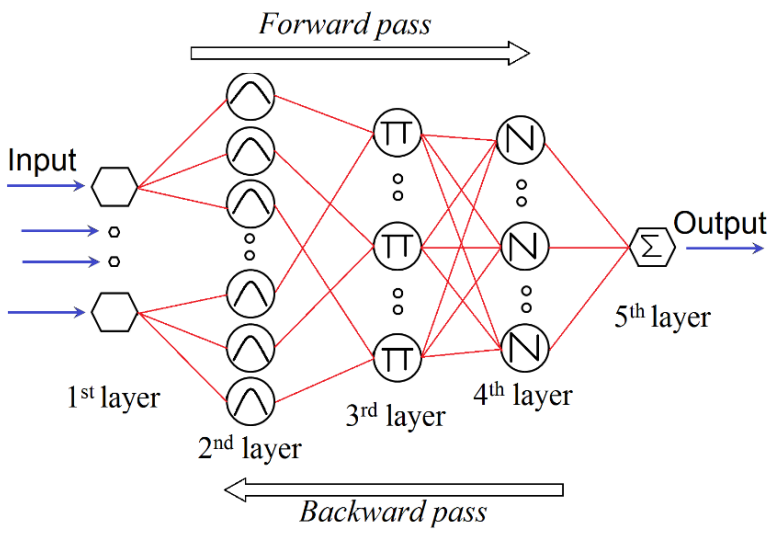

Fig. 2. Schematic architecture of network-based ANFIS. 
Hydrol. Earth Syst. Sci. Discuss., doi:10.5194/hess-2016-247, 2016

Hydrology and Manuscript under review for journal Hydrol. Earth Syst. Sci.

Published: 23 May 2016

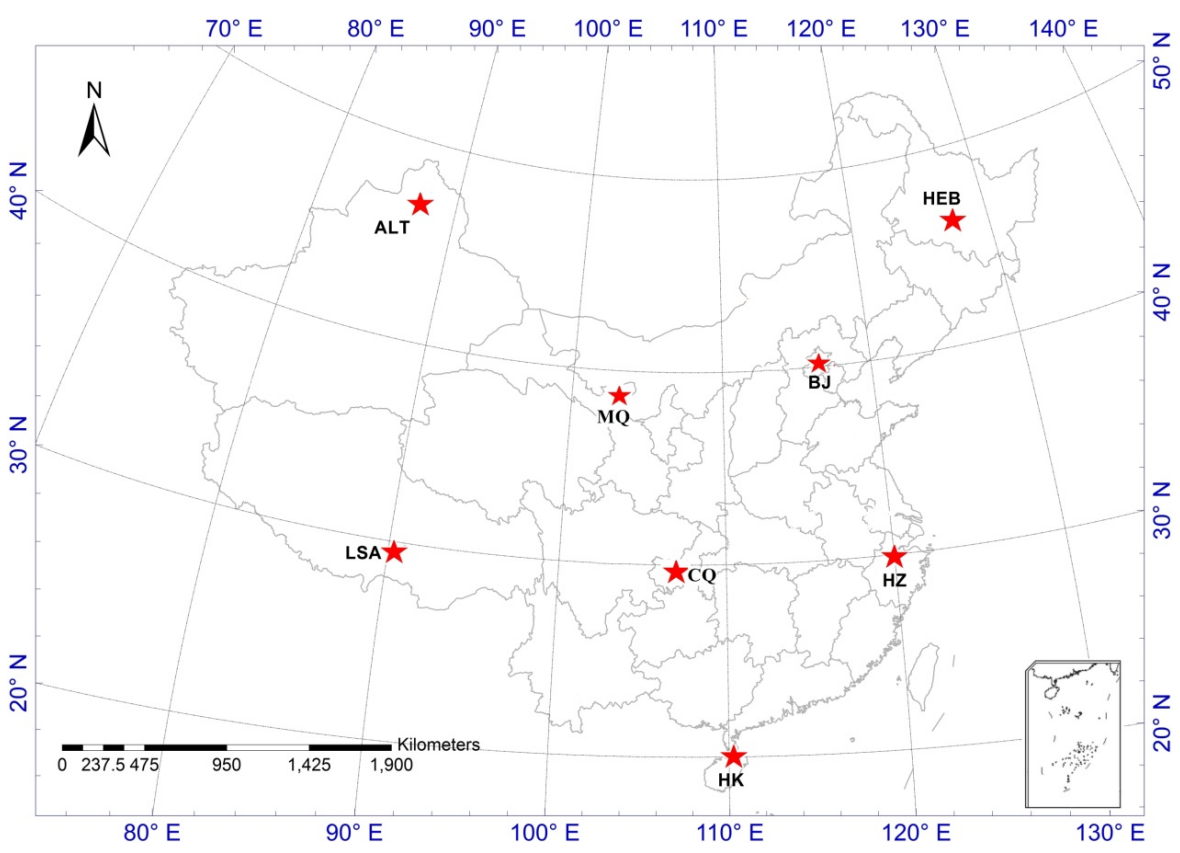

825

827

828

829

830

831

832

833

834

835

836

837

838

839

840

841

842

843

844

845

Fig.3. The geographical locations of the stations in different climatic zones. 
Hydrol. Earth Syst. Sci. Discuss., doi:10.5194/hess-2016-247, 2016

Manuscript under review for journal Hydrol. Earth Syst. Sci.

Published: 23 May 2016

(c) Author(s) 2016. CC-BY 3.0 License.
Hydrology and

Earth System

Sciences

Discussions

(c) (i)

846
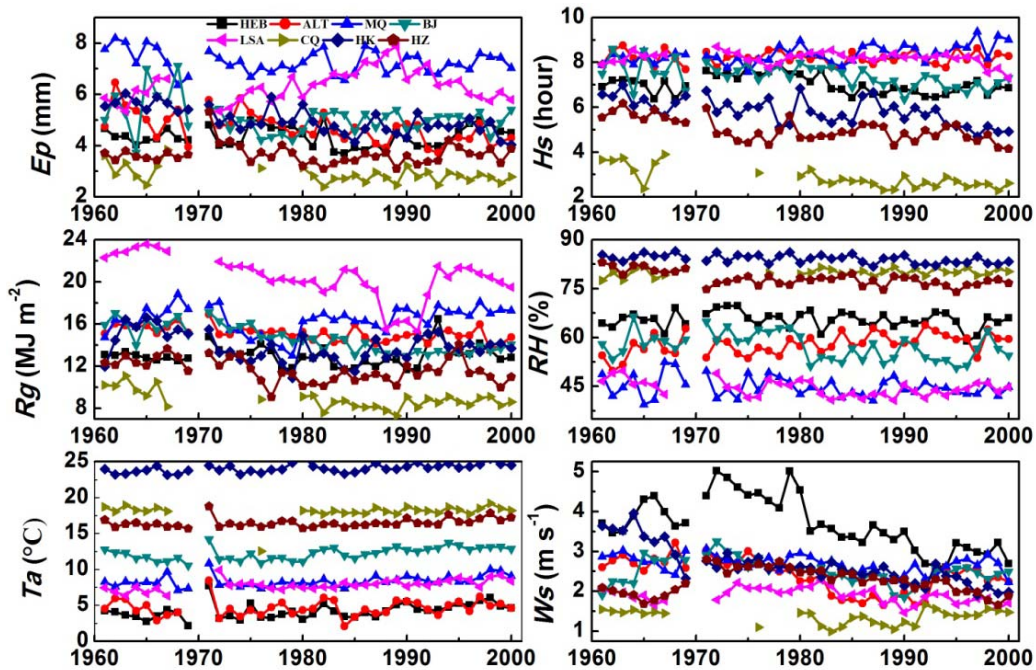

847

848

849

850

851

852

853

854

855

856

857

858

859

860

861

862

863

864

865

866

867

868

869

870

871

872

873

874

Fig.4. The annual variations of Ep and associated climatic parameters in each station. 
Hydrol. Earth Syst. Sci. Discuss., doi:10.5194/hess-2016-247, 2016

Manuscript under review for journal Hydrol. Earth Syst. Sci.

Published: 23 May 2016

(c) Author(s) 2016. CC-BY 3.0 License.
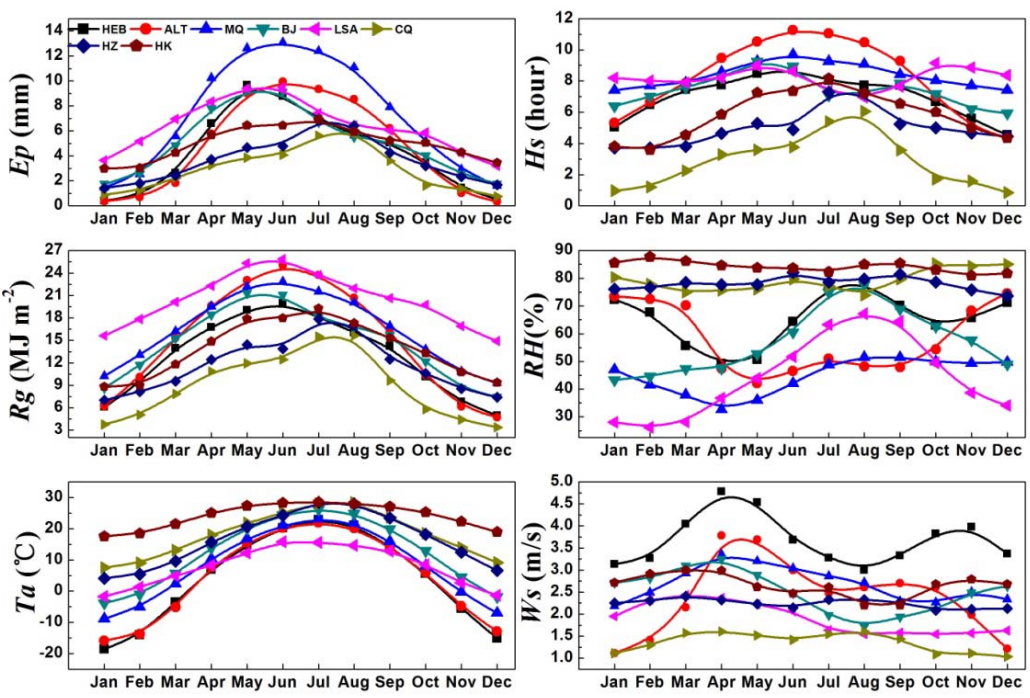

876

878

879

880

881

882

883

884

885

886

887

888

889

890

891

892

893

894

895

896

897

Fig.5. Monthly variations of $E p$ and associated climatic parameters in each station. 
Hydrol. Earth Syst. Sci. Discuss., doi:10.5194/hess-2016-247, 2016

Manuscript under review for journal Hydrol. Earth Syst. Sci.

Published: 23 May 2016

(c) Author(s) 2016. CC-BY 3.0 License.
Hydrology and

Discussions

898
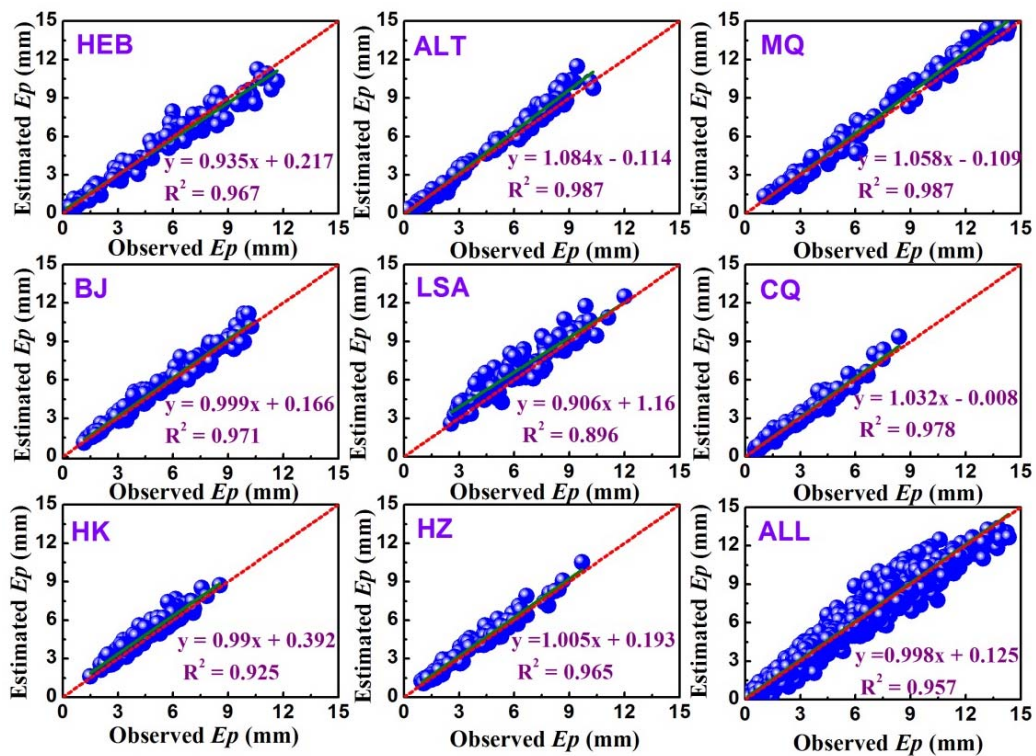

899

900

901

902

903

904

905

906

907

908

909

910

911

912

913

914

915

916

917

918

919

920

921

922

Fig.6. Comparison of the observed and estimated Ep using the optimal ANFIS-GP model during the testing period. 
Hydrol. Earth Syst. Sci. Discuss., doi:10.5194/hess-2016-247, 2016

Manuscript under review for journal Hydrol. Earth Syst. Sci.

Published: 23 May 2016

(c) Author(s) 2016. CC-BY 3.0 License.
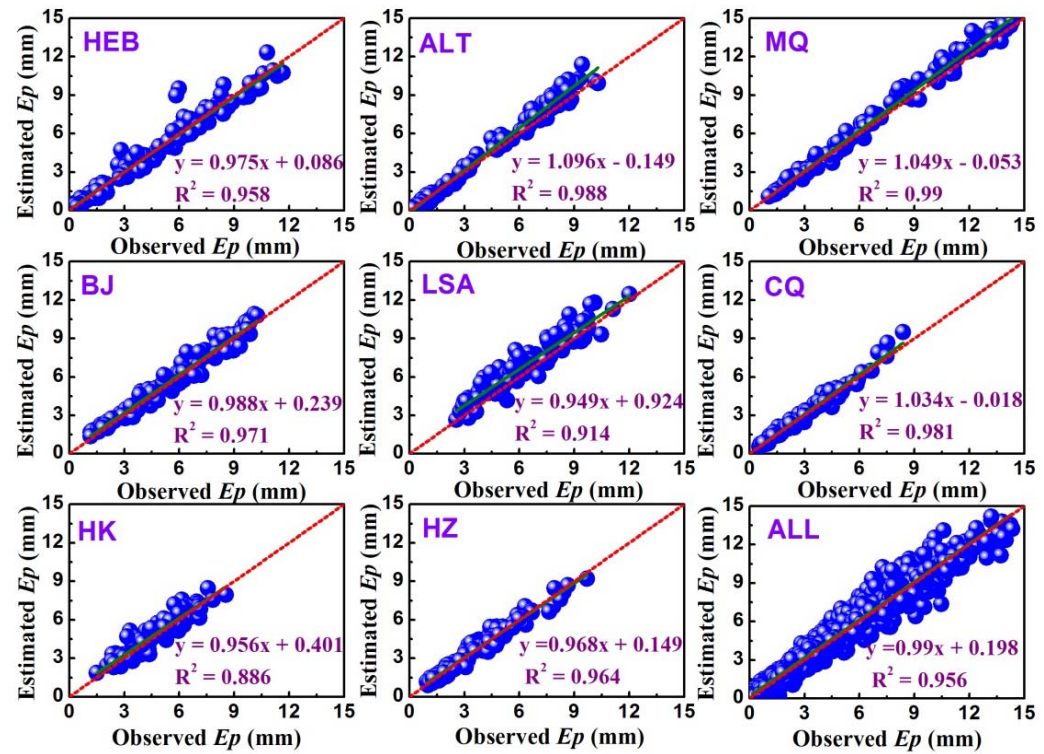

926

927

928

929

930

931

932

933

934

935

936

937

938

939

940

941

942

943

944

945

Fig.7. Comparison of the observed and estimated Ep using the optimal FG model during the testing period. 
Hydrol. Earth Syst. Sci. Discuss., doi:10.5194/hess-2016-247, 2016

Manuscript under review for journal Hydrol. Earth Syst. Sci.

Published: 23 May 2016

(c) Author(s) 2016. CC-BY 3.0 License.
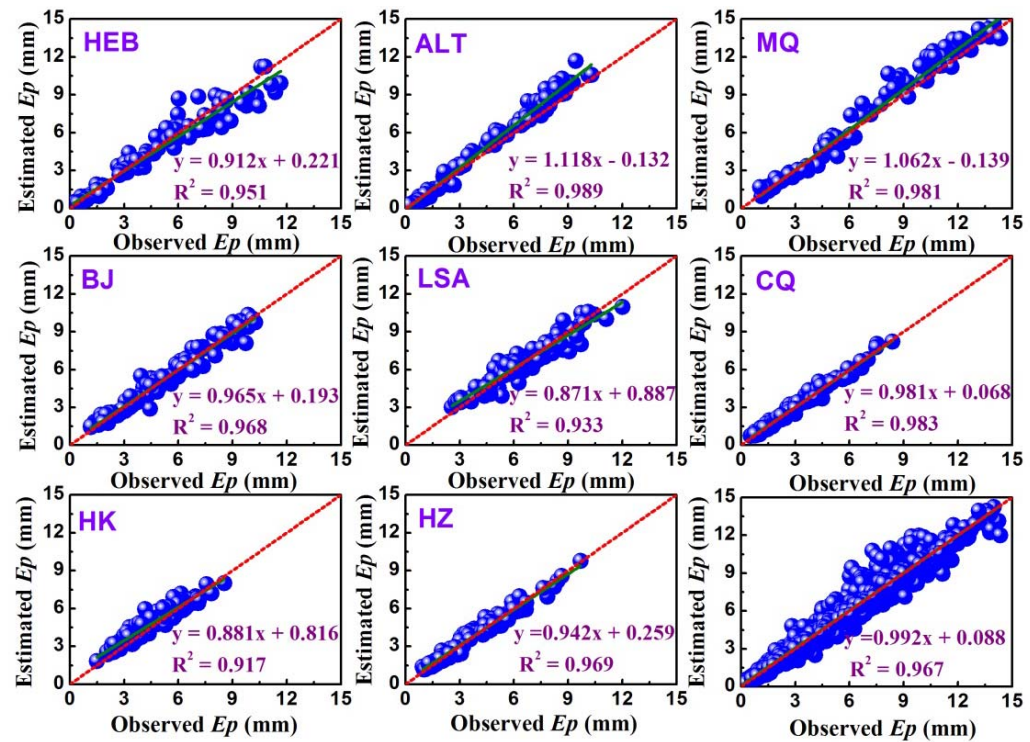

Fig.8. Comparison of the observed and estimated Ep using the optimal GRNN model during the testing period.

950

951

952

953

954

955

956

957

958

959

960

961

962

963

964

965

966

967

968

969

970 
Hydrol. Earth Syst. Sci. Discuss., doi:10.5194/hess-2016-247, 2016

Manuscript under review for journal Hydrol. Earth Syst. Sci.

Published: 23 May 2016

(c) Author(s) 2016. CC-BY 3.0 License.
Hydrology and

Discussions

(c) $\underset{\mathrm{BY}}{(i)}$

971
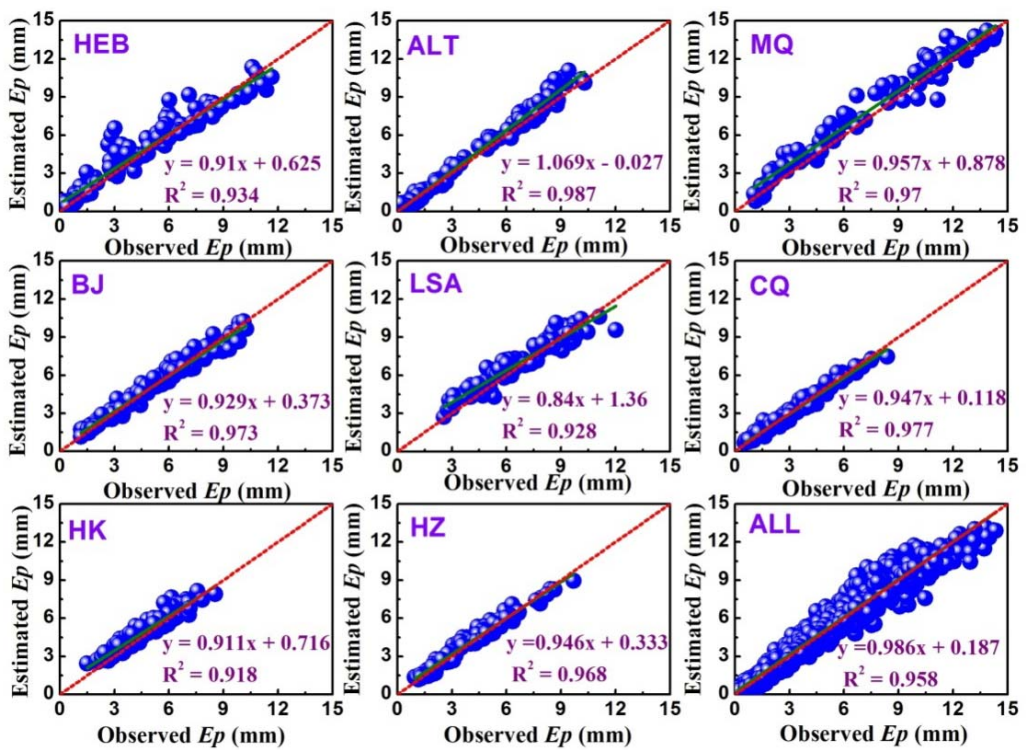

972

973

974

975

976

977

978

979

980

981

982

983

984

985

986

987

988

989

990

991

992

993

994

995

996

997

Fig.9. Comparison of the observed and estimated Ep using the optimal LSSVM model during the testing period. 
Hydrol. Earth Syst. Sci. Discuss., doi:10.5194/hess-2016-247, 2016

Manuscript under review for journal Hydrol. Earth Syst. Sci.

Published: 23 May 2016

(c) Author(s) 2016. CC-BY 3.0 License.
Hydrology and

\section{(c) (i)}

998
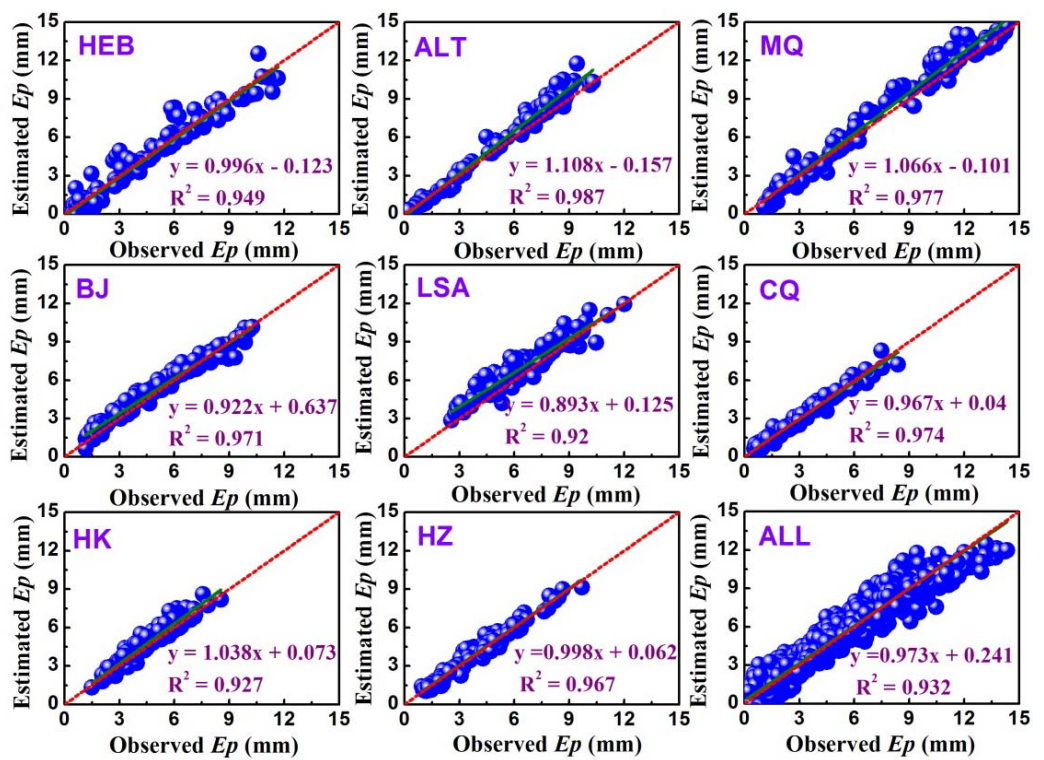

999

1000

1001

1002

1003

1004

1005

1006

1007

1008

1009

1010

1011

1012

1013

1014

1015

1016

1017

1018

1019

1020

1021

Fig.10. Comparison of the observed and estimated Ep using the optimal MARS model during the testing period. 
Hydrol. Earth Syst. Sci. Discuss., doi:10.5194/hess-2016-247, 2016

Manuscript under review for journal Hydrol. Earth Syst. Sci.

Published: 23 May 2016

(c) Author(s) 2016. CC-BY 3.0 License.
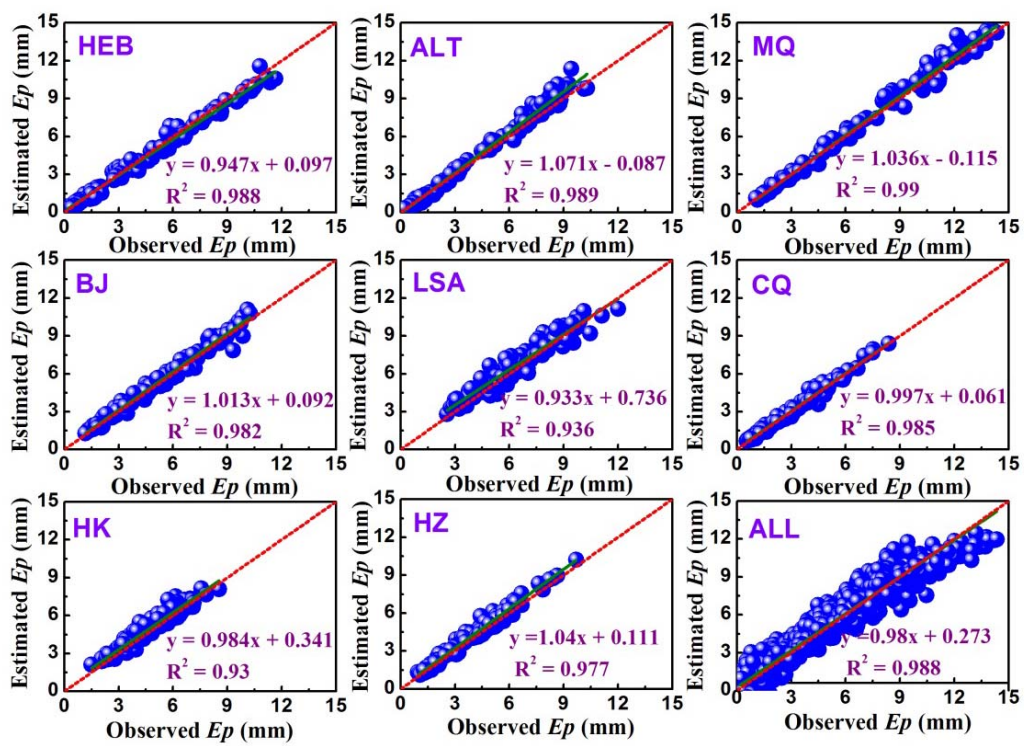

1023

1024

Fig.11. Comparison of the observed and estimated Ep using the optimal MLP model during

1025 the testing period.

1026

1027

1028

1029

1030

1031

1032

1033

1034

1035

1036

1037

1038

1039

1040

1041

1042

1043

1044 
Hydrol. Earth Syst. Sci. Discuss., doi:10.5194/hess-2016-247, 2016

Manuscript under review for journal Hydrol. Earth Syst. Sci.

Published: 23 May 2016

(c) Author(s) 2016. CC-BY 3.0 License.
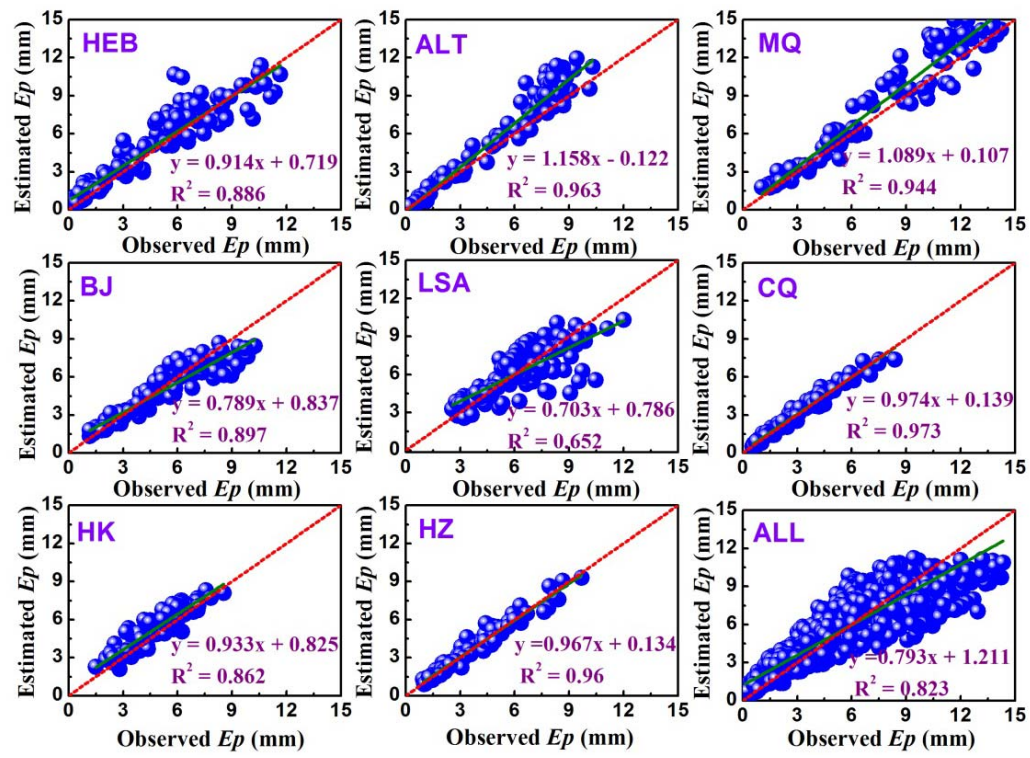

1046

1047

Fig.12. Comparison of the observed and estimated Ep using the optimal SS model during the

1048 testing period.

1049

1050

1051

1052

1053

1054

1055

1056

1057

1058

1059

1060

1061

1062

1063

1064

1065

1066

1067

1068

1069

1070 
Hydrol. Earth Syst. Sci. Discuss., doi:10.5194/hess-2016-247, 2016

Manuscript under review for journal Hydrol. Earth Syst. Sci.

Published: 23 May 2016

(c) Author(s) 2016. CC-BY 3.0 License.
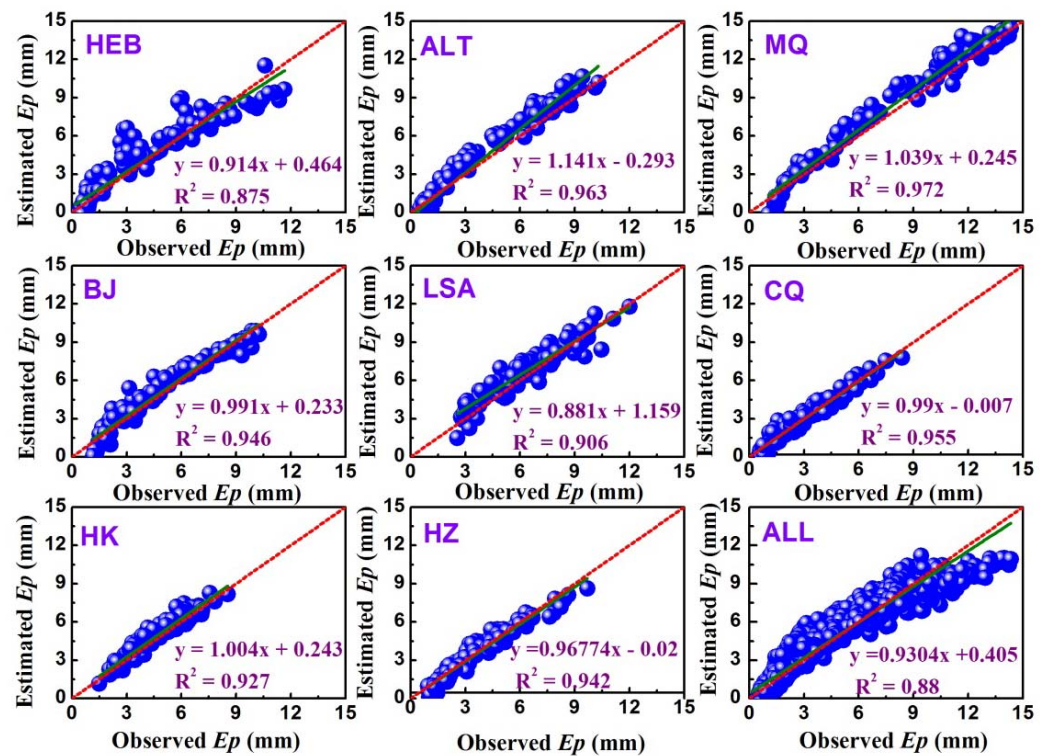

1072

1073

Fig.13. Comparison of the observed and estimated Ep using the optimal MLR model during

1074 the testing period.

1075

1076 